\title{
La fortificación en el valle del Tajo $y$ el alfoz de Talavera entre los siglos XI y XV
}

\author{
César Pacheco Jiménez \\ UNED, Centro Asociado de Talavera de la Reina (Toledo)
}

\begin{abstract}
RESUMEN El análisis de las evidencias arqueológicas junto a los datos documentales

La complejidad del poblamiento en zonas de frontera como el valle del Tajo durante

ia Edad Media dio como resultado una serie de modelos para la repoblación y el contro del territorio, que en ocasiones van bajomedievales nos permite esbozar una teoria acerca de un modelo reconvertido de asentamiento rural que será utilizado para la repoblación de esta comarca del occidente toledano.
\end{abstract}

a ser elementos heredados de la etapa

islámica; por lo que respecta a la Marca Media, y en concreto el alfoz de Talavera

(Medina Talabira) se caracteriza por la presencia de determinados enclaves con equipamientos de torres (al-bury y turris) que a modo de bastiones fortificados van

a suponer un recurso defensivo en el inestable siglo XII, sometido a frecuentes acometidas de las invasiones norteafricanas -almorávides y almohades-

- Estas torres, junto a las atalayas o almenaras de la tierra talaverana, y los recintos fortificados como Vascos o la misma Talavera, y los husun como Castros, Alija o Espejel, etc. configuraron un paisaje rural dominado por una red de fortalezas de distinta categorias y diversas funcionalidades.

Esos enclaves pasarán a la Baja Edad Media, una vez pasada la etapa de militarización, a convertirse en centros en torno a los cuales se forjarán casas-

fuertes o alquerias de señores y pobladores de la tierra de Talavera.

\section{PALABRAS CLAVE}

Fortificaciones. Torres. Valle del Tajo. Siglos $X 1-X V$.

\section{ABSTRACT}

The complesity of the colonization in frontier area, life the Tajo Valley during the Middle Ages, resulted in a series of models for repopulation and de territory control wich area going to be occasionally inherited elements of the islamic stage, in relation to Middle Mark, and specifically the Talavera's suburb (Medina Talabira) it is typical because of the certain places with towers (al-bury and Turris) thet, as a fortified bastions, will mean a defensive resource in unstable $12^{\text {h }}$ century, when it often happened many Northafricain invasions (alomoravides and almohades). These towers, as well as the wachttowers 
in the Talavera's territory, and the fortified areas like Vascos or Talavera itsame, and the husun like Castros, Alija or Espejel, formed a rural landscape that was

dominated by a fortress system of diferent categories and several functions.

Once the military stage was finished in the low Middle Ages, those places will because centres where fort-houses will be built as well as farmhouses belonping to landlords in Talavera's territory.
The analysis of archeological evidences as well as some pieces of information in medieval documents let us focus on a theory about a restructural model of rural establishment that will be used for the repopulation in this region in west of Toledo.

\section{KEY WORDS}

Fortress system, towers, Tajo Valley, $11^{\text {th }}$ $-12^{\text {th }}$ centuries

Afrontamos en este trabajo el estudio de un tipo de fortificación que posiblemente esté sometido a condicionantes de peso a la hora de su interpretación. En lo fundamental porque presenta una variedad que tan sólo permite articular hipótesis teóricas de análisis, dada la escasez de datos arqueológicos que puedan corroborar nuestros planteamientos. Aplicaremos, por tanto, otra metodología que afine el corpus argumental de nuestra comunicación.

En el antiguo Reino de Toledo, por sus propias características de evolución histórica desde la época califal hasta la consolidación del poder real en el siglo xil, pasando por la etapa taifa, nos vemos obligado a acercarnos al análisis del espacio rural circundante de las ciudades o núcleos principales de población desde una metodología basada en contrastar la documentación de mozárabes y la de instituciones coetáneas que ha llegado hasta nosotros, para sacar conclusiones que, en todo caso, estarán condicionadas por un presunto halo de inseguridad. La misma documentación nos advierte las carencias que ofrece a la hora de esbozar un cuadro de organización del sistema defensivo. Y si bien es cierto que existen estudios generales de las fortificaciones en el Valle del Tajo, tanto de la zona toledana como de la extremeña, no hay hasta el momento un enfoque global y completo de los elementos fortificados existentes, lo que lleva a considerar parcialmente el hecho. También hay que advertir que la turris, como luego veremos, es solo una pieza mas de ese mosaico fortificado que se construye en relación tanto estratégica como geográfica con el resto de elementos.

Ante tal panorama, la documentación y la toponimia tanto la que actualmente se conserva, como la localizada en las fuentes escritas pero ya desaparecidas, nos sirven de base para una reflexión sobre el complejo mundo de las fortificaciones medievales en territorios reconquistados ${ }^{1}$. Nos centramos en

Problema que ya ha sido tratado por diferentes autores en distintos ámbitos, por ejemplo $R$. VAZQUEZ ÁlvareZ, "Castrum, castellum, turris en la organización social del espacio en Castilla entre los siglos Ix al xill» en La fortaleza medieval: Realidad y simbolo. Murcia, 1998, pp. 357-365. 
estos campos dada la importancia que adquiere el uso de las fuentes documentales en el estudio de las fortificaciones en el panorama historiográfico actual $^{2}$ y el cada vez más empleado recurso del análisis de la toponimia aplicado a la arqueología ${ }^{3}$.

En el caso concreto que aquí estudiamos, Talavera de la Reina, en una etapa decisiva de su consolidación como concejo, entre finales del siglo $x \|$ y el $x{ }^{4}$ hemos tenido que apostar por un sistema de interpretación en el que la documentación y las reflexiones desde la arqueología medieval se conjugan para esbozar el problema: en sintesis, éste se centra en la búsqueda de indicios, en las referencias documentales de esta etapa, que puedan articular una hipótesis acerca de la existencia de un prototipo de fortificación que englobamos bajo el nombre genérico de turris pero que responde a una variedad de realidades tanto desde el punto de vista histórico militar, como elemento de articulación y organización del territorio. Estos modelos apuntan, además, hacia una serie de variantes que tendrian su origen en época islámica, y presuntamente, en algunos casos, en época tardoantigua ${ }^{5}$.

No obstante, como luego se intentará explicar, en la zona de Talabira, al menos, existieron distintas realidades de explotación agropecuaria, desde las habituales huertas intra y peri-urbanas, hasta las casas de labor fortificadas y/o protegidas por alguna torre, pasando por las habituales alquerias que derivarán en algunos casos a la forma de aldea castellana.

La nueva realidad socioeconómica que subsiste tras la conquista y ocupación cristiana en el área de Talavera con Alfonso VI, origina un determinado tipo de propiedad donde los magnates de las órdenes militares y los principales centros religiosos monacales de la época, amén de los dominios de la corona, van a constituir un mosaico traducido en la asignación de las tierras de regadio en torno a la

2 L. M.a Carrero Pérez, "El empleo de fondos documentales en el análisis arqueológico de la arquitectura militar. Método y consideraciones principales» en Actas del III C.A.M.E., Oviedo, 1992, vol. II, pp. 13-19.

3 Sobre este tema para la zona de Talavera vid. M. DE LA VEGA JIMENO, «La toponimia como elemento de apoyo en la investigación histórico-arqueológica en la zona occidental de la provincia de Toledo" en Cuaderna, 7-8, 1999-2000, pp. 38-53

4 Para este arco temporal tenemos algunas obras de referencia obligada: E. RODRIGUEZ-PICAVEA, La Villa y la Tierra de Talavera en la Plena Edad Media. Origenes, consolidación y crecimiento de un concejo de realengo (SS. Xi-XIII). Talavera, Excmo. Ayuntamiento, 1996. M. a J. SuAREZ ALvarEZ, La Villa de Talavera y su Tierra en la Edad Media (1369-1504). Oviedo, 1982. Y la obra clásica de J. GómEz MENOR, La antigua tierra de Talavera. Bosquejo histórico y aportación documental. Toledo, Excmo. Ayuntamiento de Talavera, 1965

5 La pervivencia de elementos fortificados de origen romano en la zona toledana está aun por analizar. En este sentido, entendemos que el excesivo peso de las corrientes de interpretación de la arqueologia islámica en la zona del Tajo y Marca Media, han podido desplazar otros posibles análisis del problema que se encaminaran al origen antiguo de algunos enclaves, hecho que la arqueologia parece demostrar. Parte de esta reflexión la tenemos recogida en nuestro trabajo "Fortificaciones y vías de comunicación en época romana y altomedieval en la zona de Talavera de la Reina (Toledo)" en Actas del $\checkmark$ Congreso Internacional de Camineria Hispánica (Valencia, 17-22 de julio de 2000), Guadalajara, Aache Ediciones, 2002, t. I, pp. 53-74. 
Vega del Tajo, como zona rica y fértil. El corpus documental se centra pues en estas instituciones.

Metodológicamente, la consulta de estas fuentes nos proporciona un enfoque de la dispersión de turres asociadas a veces a propiedades rurales de esas características en el alfoz de Talavera, desde época califal hasta principios de la época moderna; es decir, con las reservas que obliga este tipo de análisis y la información que presta la toponimia y la arqueología, nos aproximamos al campo de investigación del control del territorio y del agro talaverano.

El resultado, no obstante, de esta comunicación está sometido a una futura revisión, dentro de las investigaciones que estamos llevando a cabo sobre este particular, por lo que se ha optado por considerarla una aproximación. Las conclusiones aquí reflejadas se encuentran por tanto, en una fase de profundización que esperamos que con este congreso se vean enriquecidas.

\section{UN ÁMBITO GEOGRÁFICO DIVERSO: LA TIERRA DE TALAVERA}

El área objeto de estudio abarca un amplio territorio enclavado en las actuales provincias de Toledo, Cáceres y Avila, y que conformó históricamente, la antigua tierra de Talavera, y con más o menos modificaciones, una parte importante de lo que se considera la Marca Media (al-Tagr al-Awsat) en época andalusí. Con este referente espacial debemos apuntar que la dispersión de elementos que se ajustan al modelo de fortificación que aqui proponemos, está condicionado por el medio físico en el que se enclavan, y que desde el punto de vista geográfico conforma varios ámbitos:

La Jara, hoy considerada como una comarca geohistórica ${ }^{6}$, con entidad propia y suficiente bagaje cultural. Se caracteriza por un relieve de valles, cerros y lomas con la presencia de las rañas, donde el afloramiento de materiales cuaternarios pone su nota distintiva en el agro jareño. En torno a los cauces de ríos como el Jébalo $^{7}$, el Uso y el mismo Tajo, y arroyos importantes como el Tamujoso, o el Pedroso, todos con sus cursos hacia el norte donde se reúnen con el Tajo, se articulan muchos enclaves de poblamiento desde época prehistórica.

Actualmente se distingue entre la Jara toledana, que abarca una porción importante del sector sudoccidental de la provincia, y la cacereña, en el sector oriental de la provincia vecina; desde la óptica histórica, hay que considerarlas una unidad adscrita al alfoz talaverano, hecha la salvedad de los procesos de desmembración que éste experimentará desde el siglo XIII.

- F. Jimenez de Gregorio, Comarca de la Jara Toledana. Toledo, 1982 . Idem, El alfoz de Talavera y sus montes. Talavera, 1981.

7 G. Planchuelo Portalés, "Aportación al conocimiento de la Jara toledana: el río Jébalo" en Estudios Geográficos, 51, 1953, pp. 241-266. 
La zona denominada en las fuentes El Berrocal se refiere la parte montañosa que existe al norte de la ciudad de Talavera y que supone una emergencia de los materiales graníticos paleozoicos ofreciendo un característico relieve donde los bosques de encinas y chaparros se funden con los berrocales y cercas de piedra para prados. Numerosos arroyos y profundos valles surcan la zona, aportando un gran caudal hídrico de régimen pluvial a toda estas tierras. Fue éste un sector especialmente aprovechado desde el siglo XII, siendo muy circunstanciales sus asentamientos en épocas anteriores ${ }^{8}$. En estas elevaciones norteñas de Talavera se articula un buen sistema de atalayas de vigilancia tanto para el norte, tierra de Avila, como para el sur, divisando el amplio valle y vega del Tajo a su paso por Talavera.

Esta zona del Berrocal constituye la antesala geomorfológica de la Sierra de San Vicente, un conjunto de grandes elevaciones que se dibujan en el paisaje más al norte, sirviendo de barrera natural de defensa del valle del Tajo por esa parte, y a la vez, puerta de entrada al ámbito del Tiétar y la sierra de Gredos, tierras del concejo abulense en la época que tratamos. El control de este territorio queda manifiesto por la ubicación de algunas fortalezas - atalaya del Cerro de San Vicente, posterior fortaleza cristiana del siglo xII, enclave del Castillo de Bayuela, etc.-, en un agreste relieve pero de gran frondosidad utilizando además durante la Edad del Bronce determinados enclaves de altura: Cerro del Castillo, Cerro del Oso, Milanillo, etc.

Tanto la vertiente norte como la sur de esta sierra será aprovechada para la instalación primero de pequeños reductos poblacionales en torno a vias de comunicación importantes, y cuencas de arroyos generosos en agua. Precedentes de una ocupación islámica mediatizada por el factor militar de control del territorio, y núcleos de repoblación incrementados desde el siglo XII ${ }^{9}$.

El valle del Tajo en la zona de Talavera ha venido siendo objeto de asentamientos de comunidades humanas, de carácter diverso, desde los estacionales y, más o menos temporales, de época paleolítica, hasta los poblados y campamentos del Bronce Medio que recientemente se están localizando en pequeñas elevaciones de aluviones cuaternarios en las terrazas laterales del río. En el mismo solar de la ciudad de Talavera se enclavó igualmente un asentamiento de la Edad del Bronce, al tiempo que las investigaciones arqueológicas están demostrando la existencia de estructuras prerromanas, anteriores a la fundación de la urbe romana en torno al siglo । a. C. La propia Caesarobriga, convertida en municipio en época flavia, deberá su desarrollo a la rica y fértil vega circundante, depósito generoso del Tajo durante el cuaternario.

s Véase C. PACHECO JiMÉnEz y otros, Mejorada: Historia de una villa de Señorio. Talavera, 2000, donde analizamos la evolución de los asentamientos en esta zona desde la prehistoria. Sobre la comarca $F$. JiMEnez de Gregorio, La comarca de El Alcor y el Berrocal. Toledo, 1997.

${ }^{9}$ J. Hernandez Garcia, “La Repoblación en la Sierra, s. xi al xiv» en Aguasal, n. 21,22 y 23 (2001). Jiménez de Gregorio, F., Comarca de La Sierra de San Vicente. Toledo, 1991. 
La vega que se extiende longitudinalmente, de este-oeste, siguiendo el curso del río, ha dejado una morfología asimétrica en sus márgenes ${ }^{10}$ siguiendo la norte una disposición de terrazas fluviales escalonadas a partir de la talweg, terrazas encajadas con sustrato oligoceno aflorante bajo la acumulación detrítica ${ }^{11}$. Hasta cuatro niveles se distinguen que van desde los 5-7 $\mathrm{m}$ en la terraza inferior o IV, y alcanzan los 95-100 $\mathrm{m}$ la superior o I. Sin embargo, la margen sur tiene un relieve más accidentado con grandes contrastes en unos terrenos, el llamado Cerro $\mathrm{Ne}$ gro, sobre materiales arcósicos del terciario. En esta misma margen, pero más al este, cerca de La Pueblanueva, el relieve aterrazado se presenta también de forma más clara ${ }^{12}$.

Por otra parte, las características climáticas de nuestro entorno, enclavadas en lo que podemos denominar clima mediterráneo con influencia continental, con tendencia a la extrema aridez en época estival, han condicionado el desarrollo de determinadas formas de explotación de la tierra en esta área desde la antigüedad. Los recursos hidrológicos en la zona no son escasos, existiendo numerosos arroyos y arroyuelos, entre los que cabe destacar, aparte de los ríos Tajo y Alberche, el Papacochino, Berrenchín, Portiña, Albaladiel, Bárrago, Merdancho, Ardagüilejo, Arroyo de la Sal, de las Parras, etc. Esta red hidrográfica de superficie se complementa con los acuíferos subterráneos que proporcionan una reserva importante para los fines agrícolas.

En algo que suelen incidir las descripciones del entorno de Talavera es la fertilidad de los campos circundantes de la vega del río, ámbito que después de un uso casi reiterado desde la antigüedad, se mostraba como un motor económico para el sostenimiento propio de la ciudad.

A caballo entre el ámbito toledano y el extremeño, se sitúa también el llamado Campo de Arañuelo, sector que por sus propias condiciones físicas, de relieve suave de llanura, y la pervivencia del bosque de encinar y alcornoque, fue apto para la aparición de grandes dehesas ${ }^{13}$. La repoblación en este sector en el siglo XIII favorece la creación de pueblas en lo que constituía el sector más meridional del alfoz abulense, lo que explicará también la aparición de nuevos elementos for-

10 J. C. JIMEnez RodRigo, "Geografía física en los alrededores de Talavera de la Reina: Geomortología cuaternaria» en Cuaderna: Revista de estudios humanisticos de Talavera y su antigua tierra, Talavera, 3. 1996, pp. 5-20

11 Sobre el cuaternario y las implicaciones hidrogeológicas en esta parte del Tajo pueden verse los siguientes trabajos: A. SASTRE MERLIN, "Características hidrogeológicas de los materiales detríticos de edad terciaria y cuaternaria de los alrededores de Talavera de la Reina (Toledo)" en I Simposio Nacional de Hidrogeología. Valencia, 1976, t. I, pp. 436-449. Nanmany SAID SHAFIC: Estudio del Cuaternario en la región de Talavera de la Reina (sector medio de la cuenca del Tajo). Tesis de licenciatura. Inédito. Madrid, 1973.

${ }^{12}$ F. J. DiAz GOMEZ, "Aproximación a la cronoestratigrafía y cartografía del área situada en el sistema de terrazas al Este de Talavera de la Reina (Pueblanueva). Posibles yacimientos arqueológicos" en Actas de las Primeras Jornadas de Arqueologia de Talavera de la Reina y sus tierras. Toledo, Diputación Provincial, 1992, pp. 191-299.

13 J. Corchon Garcia, El Campo de Arañuelo. Madrid, 1963. Jiménez de Gregorio, F., El Campo del Arañuelo toledano. Toledo, 2000. 
tificados y el aprovechamiento de otros muchos de época islámica ${ }^{14}$. Y la creación de señoríos con un gran peso político como el Oropesa ${ }^{15}$. En el extremo sur del Campo de Arañuelo, en torno al curso del Tajo, fortalezas de origen islámico como Castros, Alija, Espejel o Peñaflor constituyen entonces una red defensiva de primer orden, dentro de la red defensiva de la Marca Media.

Esta disposición geográfica y morfológica del relieve influye sin duda en la distribución espacial de la tipología del hábitat rural en esta época, condicionado, entonces, no sólo por la localización en determinado tipo de terreno y su consiguiente grado de productividad agraria, sean espacios irrigados o no, sino por las especiales condiciones geoestratégicas y políticas que este territorio experimenta entre los siglos XI y XIII.

\section{LA TURRIS: UN MODELO DE FORTIFICACIÓN EN LA ZONA DE TALAVERA ${ }^{16}$}

Partiendo de la casuística que encontramos a la hora de analizar las referencias documentales se requiere perfilar un campo teórico de clasificación de las tipologías de fortificaciones rurales en este territorio que estudiamos. Conviene en primer lugar, aclarar que la definición de estos modelos son una mera aproximación al problema que por nuestra parte queda sin resolver plenamente. Las implicaciones que el fenómeno repoblador, a partir del siglo XI, tienen en la concepción y organización del nuevo espacio a repoblar y a asegurar siempre estuvieron condicionadas por un carácter provisional. $Y$ de acuerdo con esta provisionalidad surgida de esa especial situación fronteriza y de inseguridad durante todo el siglo $\mathrm{X} \| 1^{17}$, podemos fijar a priori unos modelos que se fundamentan en las necesidades defensivas del momento.

El espacio rural, entonces, tanto de la vega como de las elevaciones se encuentra en esta etapa sometido a una estrecha vigilancia, ofreciendo un panorama que puede compararse con otras zonas de la Peninsula donde se viven situaciones parecidas.

El modelo de almunia-torre, término que admitimos como válido según lo acuña Eritja Ciuró ${ }^{18}$, tiene una aplicación aproximada en esta parte del valle del Tajo,

14 J. L. Moreno Nuñez, Avila y su tierra en la Baja Edad Media (SS. XII-xv). Avila, 1992. Del mismo autor "Fortalezas en el extremo meridional del alfoz de Avila (Notas sobre su pasado medieval)" en Castillos de España, n. ${ }^{\circ} 23$ (junio 1985), pp. 31-38.

15 A. Franco Silva, "Oropesa: el nacimiento de un señorío toledano a fines del siglo XIV" en Anuario de Estudio Medievales, $\mathrm{n} .{ }^{\circ}$ 15, 1985.

${ }^{16}$ C. PACHECO JIMENEZ: «Turris en el area de Talavera de la Reina: un modelo de fortificación en el valle del Tajo:". Actas del Il Congreso de Castellologia lbérica (en prensa).

17 C. PACHECO JIMENEZ, "Un espacio en conflicto en el siglo Xi: Talavera en una etapa de transición (1086-1126)" en Alcalibe (Revista del Centro Asociado a la UNED de Talavera de la Reina), 1 (2001), pp. 97-112

18 Erit.ja CIuro, Xavier, De l'Almunia a la Turris: organització de l'espai a la regió de Lleida (segles XIXiii). Zaragoza, 1998. 
o al menos nos sirve de referente claro para explicar un modelo de hábitat que parece tener cierta implantación.

En el marco del problema se encuentran algunas aportaciones de diferentes autores. Eritja Ciuró, que se ocupa de la comarca de Lleida, explica que en la terminología feudal hay cierta confusión cuando se menciona uno u otro término, llegando en ocasiones a asociarse la existencia de una turris con una almunia ${ }^{19}$; no obstante, hay que advertir que la forma almunia en este territorio es una adopción feudal del término andalusí; teniendo un carácter peri-urbano y a veces vinculada a un antropónimo ${ }^{20}$. Las dos funciones - la agropecuaria y la defensiva- que pueden parecer inconexas, llegan a identificarse en lo formal: por una parte la almunia llegaría a definir la explotación agraria en conjunto, y por otra, la turris se refiere al núcleo del hábitat, el edificio de residencia, defensivo y con un marcado carácter simbólico. Con el tiempo, la turris pasa a denominar la explotación y la torre defensiva, quedando en la toponimia y en las referencias documentales este término aislado.

Al mismo tiempo, este autor concreta una idea que nos parece apropiada para explicar el complicado asunto del hábitat rural andalusí en la zona de Talavera y cómo evoluciona o se reconvierte bajo la ocupación cristiana del territorio; según se entiende el concepto turris-almunia, éste puede albergar diversos modelos de explotación, por lo que no puede descartarse la posibilidad de incluir explotaciones andalusies de tipo comunal (qarya, bury) que con la reconquista devendrian en dominios señoriales, por tanto almunias feudales ${ }^{21}$. Algunas de las torres (turris o bury) que se prodigan por el área del alfoz talaverano sin duda pudieron tener un origen andalusí, fundamentalmente en época taifa, que fueron reedificadas por los pobladores cristianos castellanos y abulenses para hacer efectivo el control del territorio agrario.

En esta tipología, sin embargo, habría que distinguir aquellas construcciones eminentemente de carácter militar —atalayas o similares - de las torres asociadas a casas de labor o al menos que asumian un papel de almunia en el agro talaverano, conformando quizá un modelo más cercano a las casas-fuerte o almunias torreadas ${ }^{22}$.

Entre la turris y la almunia, considerada ésta como casa de campo lujosa y provista de comodidades y elementos para la recreación y el descanso tuvo que haber

19 Ibidem, p. 13

20 Es habitual que el nombre de al-munya vaya casi siempre determinado por otro de persona o de Iugar. G. Abd al-KariM, La España musulmana en la obra de Yaqubt. Granada, 1974, p. 35.

21 ERITJA Ciuró, op. cit., p. 34.

22 Idea que hemos desarrollado a la hora de analizar el modelo de las almunias islámicas y la huerta cristiana de la campiña talaverana. Véase nuestro trabajo «Almunias en la Talavera medieval: Aproximación histórico-arqueológica al estudio del espacio rural islámico en el occidente de la taifa toledana" en Actas del Congreso Internacional Entre el Califato y la Taifa: Mil años del Cristo de la Luz (Toledo, 14, 15 y 16 de diciembre de 1999). Toledo, Asociación de Amigos del Toledo Islámico, 2000, pp. 369-386. 
un proceso de fijación de modelos intermedios que marcan diferencias cronotipológicas. Nos referimos por ejemplo a otro tipo de residencias palatinas periurbanas, con vistosas qubbas y rodeadas de murallas, torreadas, según se ve en Los Castillejos, cerca de Murcia o la Alfajería de Zaragoza ${ }^{23}$. En este tipo pensamos que tendría cabida el palacio de Torres Salinas, que por los indicios arquitectónicos conservados de época medieval, podría responder a este modelo de almunia torreada (de planta quadribugium) aunando finalidades de recreo, explotación agropecuaria y control de las salinas adyacentes.

Esta relación entre torres de defensa-almunias y/o huertas periurbanas se da también en la zona levantina. En el área rural de Valencia tenemos el mismo fenómeno ${ }^{24}$. Bazzana y Guichard estudian las fortificaciones de la huerta valenciana, concluyendo que son construcciones tardias, en época anterior a la conquista cristiana de Jaime 1, y se percibe el hábitat disperso de esta región, organizado en pequeños distritos administrativos que dividen el fahs (alfoz) de la ciudad. Sin embargo, algunas de estas pueden ser anterior a juzgar por las menciones de la Primera Crónica General del asedio y toma de Valencia por el $\mathrm{Cid}^{25}$.

Igualmente, la zona andaluza de Baza presentaba un paisaje salpicado por torres entre la huerta frondosa y cargada de árboles frutales, según recoge Fernando del Pulgar: "avia más de mill torres pequeñas, porque cada vecino de aquella çibdat que tenia en ella alguna parte, facia una torre cercana a sus árboles; y aquello que le pertenecia se regaua con açequias de las muchas aguas que desçienden de aquella parte de la sierra. E en cada pertenencia avia tantos y tales hedificios que forticauan toda la huerta" 26

En Almeria también se registran este tipo de torres en pleno siglo XI: Ibn Abbás, ministro del reyezuelo Zuhayr el Esclavo, gustaba de retirarse a una torre - bury - que poseía cerca de la ciudad ${ }^{27}$. La documentación cristiana de las ciudades reconquistadas también cita frecuentemente torres de defensa apostadas en las huertas cercanas; asi ocurre, entre otros, en los casos de Tudela, Murcia o Málaga. En ésta ciudad, el paisaje de su entorno suscitó la admiración de los conquistadores. Diego de Valera lo describía con estas elocuentes palabras: "en la sierra más cercanas ay también viñas y arboledas e casas e torres que es cosa muy fermosa de ver» ${ }^{28}$.

${ }^{23}$ B. Pavón Maldonado, Tratado de arquitectura hispanomusulmana, 2: Ciudades y fortalezas. Madrid, 1999, p. 107

24 A. Bazzana y P. Guicharo, "Les tours de defénse de la Huerta de Valence au XIII siècle" en Mèlanges de la Casa de Velázquez, 14, 1978, pp. 73-105

${ }_{25}$ E. MANZANo MOREno, "El regadio en al-Andalus: Problemas en torno a su estudio", En la España Medieval, V, 1986, vol. I, pp. 617 y ss.

${ }^{26}$ L. Torres Balbas. Ciudades Hispano-musulmanas. Madrid, Instituto Hispano-Arabe de Cultura, 1985, p. 153

27 Manzano Moreno, op. cit., pp. 619-620.

28 Diego De Valera, Crónica de los Reyes Católicos. Ed. J. M. Carriazo, Madrid, 1927 
Asegura Ruiz Povedano que este hábitat rural malagueño estaba compuesto básicamente por alquerias más o menos próximas a la ciudad y por un hábitat disperso de casas de campo, a la que se refería al-Saqundi, también llamados cortijos y almunias, que servían de recreo, esparcimiento y descanso; según la experiencia de Ibn Said "nosotros fuimos a un carmen en el que permanecimos el tiempo que duró la cosecha y lo recordamos entre los dias más felices pues la blancura de sus torres entre el verdor de sus árboles, junto con su simetria y abundancia me trageron a la memoria los versos dell Katib Abu-l-Abbas de Silves: "Vi una vez Málaga/ cuando habian adornado su tierra con torres... " Estas alquerías presentaban una desigual configuración en cuanto a número de casas, calles, servicios y equipamientos, aunque casi todos ellos se aglutinaban en torno a una torre y fortaleza y una mezquita-oratorio ${ }^{29}$.

Las características del paisaje de los alrededores de las ciudades hispanomusulmanas y con claras pervivencias durante las posteriores cristianas ofrecen una serie de elementos constructivos, tanto residenciales como productivos y defensivos entre los que habria que contar con las torres. Epalza asegura que "puede considerarse hábitat disperso periurbano, exterior a las medinas o alquerías, algunos asentamientos militares, como pueden ser las torres defensivas de la zona periurbana, en llano o en altura. Son puntos muy limitados, con escasísima guarnición, más con función de vigilancia que de acción bélica, que no hay que equiparar a otros espacios con función militar, como las alcazabas de las ciudades y los castillos de las zonas rurales de alquerias ${ }^{30}$. También Torres Balbás describe ese paisaje con casas de campo -almunias y alquerías-, torres y palacios, entre huertos, jardines y arboledas ${ }^{31}$.

Junto a estos casos de ciudades con un pasado hispanomusulmán y en los que se observa un determinado modelo de torre de campiña, vinculado o no a un caserio o alquería, en la zona de Talavera la muestra de turres nos indica una mayor variedad. Es cierto que la herencia islámica, y posiblemente hispanorromana y visigoda, en el Valle del Tajo es tan significativa como para aportar casos y ejemplos evidentes de una organización espacial caracterizada por estos conjuntos: alquería con torre y demás dependencias. Al pasar estos territorios a manos cristianas estos modelos se transmiten y además se perpetuan con un cierto grado de adaptación a los procesos de producción agropecuaria y a nuevas necesidades.

Pero lo que no se pierde es el vínculo a ese carácter defensivo que se alcanza, de tal manera que las antiguas alquerias se convierten en aldeas con esquemas organizativos cristianos, donde las relaciones feudales pueden establecer impor-

J. M. ${ }^{a}$. Ruiz Povedano, J. M. ${ }^{a}$. , Málaga, de musulmana a cristiana. Málaga, 2000, p. 64.

"3o M. DE EPALZA, "Espacios y sus funciones en la ciudad árabe" en Simposio Internacional sobre la ciudad islámica. Zaragoza, 1991, p. 12.

31 L. TORRES BALBÁS, "Los contornos de las ciudades hispanomusulmanas" en Al-Andalus, XV, 2. 1950, p. 303. 
tantes cambios físicos pero sobre todo en las relaciones sociales de los habitantes con los propietarios. El modelo constatado en la tierra de Talavera en los siglos XIII y xIV se concreta en la dotación de un cortijo - tipología de labranza que puede haber llegado al área talaverana por influencia de los emigrantes mozárabes andaluces en el siglo XII, y que se ha mantenido en la zona de la Jara hasta el siglo $x x^{32}$. La dispersión de estos núcleos rurales en torno a, o junto a una turris dibuja un paisaje habitual en otros centros urbanos y sus campiñas circundantes del sector andaluz ${ }^{33}$.

Destaca, pues, que en la configuración de estos dominios rurales, propiedad de gentes residentes en la ciudad, la existencia de torres de defensa (bury) parecen estar protegiendo cada finca, y podían disponer de abrigos subterráneos para refugio de los campesinos en caso de ataque enemigo. Este asunto tiene su reflejo en las citas de Ibn Luyun ${ }^{34}$, que en su Libro de Agricultura dice que es recomendable la construcción de una torre habitable ("Bury sakani») y advierte que la propiedad ha de estar cercada con una tapia «hizar».

La configuración de los dominios rurales, como dice Manzano, se presenta, por consiguiente, fuertemente influida por las necesidades de protección de los mismos, por lo que no es extraño encontrar en la documentación torres formando parte del paisaje agrario bajomedieval, herederas de sus antiguas funciones de vigilancia ${ }^{35}$. Ello se concreta en la construcción de torres de defensa y vigilancia que vienen a constituir asi un elemento más en la ordenación de los territorios rurales cercanos a las ciudades.

Hasta qué punto podemos aplicar al pié de la letra este modelo en la ordenación del espacio rural de Talavera es algo complicado. No obstante, y a pesar del

${ }^{32}$ El cortijo como unidad agropecuaria puede aparecer bajo el nombre de labranza en muchos casos de la Jara. Vid. A. DIEZ PEREZ, "Las labranzas de la Jara" en Castilla Folk: Revista de música y cultura castellanas, 1, 1993, pp. 8-13. La forma cortijo o curtijo que se registra en la toponimia popular de la Jara parece relacionarse con corte, derivación de la latina cohor/cohortis (de hortus), en el sentido de recinto cerrado o corral. Una realidad constructiva que tiene su extensión en la zona talaverana y en la misma villa, donde existió una Puerta de Cortes o Kurtis, documentada ya fuentes mozárabes de 1142, la conocida posteriormente como Puerta de Cuartos (vid. C. PACHECO JIMENEZ, Las antiguas puertas de Talavera de la Reina: Estudio histónico y arqueológico. Talavera, 2000, p. 161; y del mismo El Barrio de la Puerta de Cuartos: Historia social y cuitural. Talavera, 1993).

33 A. Martinez Castro y F. J. Tristell. Muñoz, "Localizados los restos de la Torre de Albaén, un importante bastión almohade del noroeste de la campiña cordobesa (términc municipal de Córdoba)" en Qurtuba, estudios andalusies, $3,1998, \mathrm{pp}$. 256-258. F. SANCHEZ VILLAESPESA, "Las torres de la Campiña de Córdoba en el siglo XIII. Un sistema de defensa de las comunidades rurales en época almohade" en Qurtuba, estudios andalusies, n. 1 (1996), pp.157-170. M. JimENEZ PUERTAS, "Asentamientos rurales y frontera: las torres de alqueria de la tierra de Loja en época nazari» en Actas de ias III Jornadas de Arqueologia Medieval (Berja, 2-5 de noviembre de 2000): Asentcimientos rurales y territorio en el mundo mediterráneo en época medieval. Granada, Athos-Pérgamos, S. L., 2002, pp. 390-421.

34 J. Eguaras Ibainez, Ibn Luyun. Tratado de agricultura. Granada, 1988.

35 En un documento de 1142 , Alfonso VII dona al arzobispo Raimundo varias propiedades entre ellas una viña en el valle de Cobisa, en el que se recoge una torre en una viña: "aliam (viña) in ipsa valle (de Cobisa) ante turrem custorum vinearum: otra vina en el mismo valle delante de la torre del guarda de las viñas"”. Vid. J. A. GaRcia LuJÁn, Privilegios reales de la catedral del Toledo (1086-1462). Toledo, 1982. Vol. II, p. 49 . 
protagonismo que estas bury toman en la etapa de reconquista y primera repoblación cristiana del área talaverana creemos que hay argumentos suficientes para identificar algunas de ellas como herederas de antiguas almunias-torres andalusies; transformadas cuando no se encontraron totalmente destruidas en puntos estratégicos de control del territorio y como recurso defensivo para el agro talaverano.

Curiosamente, la mayoría de los enclaves con el topónimo torre en el sector de Talabira se localizan en terrenos elevados de las terrazas superiores del Tajo, o en torno a los valles de arroyos secundarios; tan sólo unos pocos ejemplos se ubican en la denominada Vega: Torrejón de la Alcoba, Torre Salinas... Y muchas de ellas en torno a importantes vías de comunicación, como las situadas en las proximidades de la antigua calzada romana entre Mérida y Toledo. Esto conllevaria a concebir una necesidad de vigilancia geoestratégica a la vez que se comparte con la protección del agro, en un terreno caracterizado por el bosque de encinas y vegetación mediterránea que se aplicaría más bien a una economía pastoril de fácil control y movilidad.

Con este panorama, podriamos atribuir una diferenciación entre las torres situadas en la vega, terreno de gran calidad para el aprovechamiento agrario de regadío, que estarían vinculadas a una tradición hispanomusulmana de almunia-torre durante el periodo taifa, readaptadas en época cristiana; y de otro lado, la fundación de nuevas torres, con sensibles diferencias de las atalayas localizadas en los montes del norte de Talavera: Cerro Malojo, Segurilla, Mejorada, Cardiel y Cerro San Vicente, torres que responden a un modelo de repoblación, tanto al norte como al sur del Tajo, y una nueva forma de articular el control y vigilancia de un territorio en continua alarma e inseguridad, sobre todo durante el siglo XII como ya hemos visto.

Hay que tener en cuenta que las especiales condiciones del poblamiento de la Marca Media ofrecieron igualmente una singular forma de organizar el territorio, y por ende, el establecimiento de esa red defensiva jerarquizada en toda el área. La pervivencia o no de esa red en las mismas condiciones es algo que debe dilucidar la arqueología, pero los indicios históricos y documentales nos indican que algunos de los enclaves con ascendencia islámica son aprovechados por los nuevos pobladores cristianos, mientras que surgen de nuevo una serie de elementos fortificados defensivos y con una función estrictamente de vigilancia que nos ayuda a comprender las coordenadas de organización territorial y los factores de localización poblacional.

Hablar de bury en la zona talaverana es admitir que una determinada forma de solución arquitectónica para el control y vigilancia del término y principales vías de comunicación tuvo su origen en época hispanomusulmana, cuando no aprovecha restos romanos o visigodos anteriores ${ }^{36}$. De estas bury a la realidad conceptual y

36 C. PACHECO JIMÉNEZ, "Fortificaciones y vías de comunicación en época romana y altomedieval en la zona de Talavera...". op. cit. 
lexicológica turris (torre) en sentido amplio, hay un proceso de adaptación no sólo en la toponimia y en la lengua sino en su adaptación cultural y geoestratégica del fenómeno.

En efecto, las furres pueden haber pasado a identificar una serie de construcciones, bien de nueva planta, o bien aprovechando restos anteriores. En las crónicas medievales ${ }^{37}$ la torre representa muchas realidades, y su significación lexicológica viene, a veces, a confundir el verdadero hecho físico que representa. Aquí nos interesa la acepción relativa a edificios exentos alejados del perímetro de las ciudades fortificadas, caso de Talavera, y que están cumpliendo una función defensiva no menos importante. En la Crónica de Sahagún (s. XII) se utiliza también con este significado, y en la Crónica de la Población de Avila (s. XIII) la torre es una edificación similar a la atalaya, en el sentido de bastión de la reconquista allí donde no hay poblados cristianos ${ }^{38}$. En la Chronica Adefonsi Imperatori ${ }^{39}$ a partir del significado clásico y concreto de "torre" este vocablo extendió su acepción pasando a significar también castillo, ciudadela, atalaya defensiva $(1,37)$, pero también campanario, cárcel o palomar.

Igualmente, a la luz de los datos que se aportan en la documentación cristiana entre los siglos XII y XVI, los topónimos bajo la forma torre o derivados están traduciendo primero una realidad constructiva original -bien sea de época antigua o alto/plenomedieval- y después una herencia nominativa en la designación de ciertos parajes que pasan a los documentos con los mismos nombres que se venian utilizando cuando los elementos defensivos fortificados estaban en pie, fundamentalmente entre el siglo $1 \mathrm{x}$ y el XIII.

No es por ello extraño encontrar escrituras de compraventa, deslindes, o alusiones geográficas a lugares, donde el topónimo torre en particular, o utilizado como una de las partes de un nombre compuesto, designa también a una viña, un pago, un ejido, dehesa, etc. Otras veces, será la similitud y ambivalencia de la funcionalidad de los edificios-torres lo que aporta datos de interés en la documentación. Es el caso de los topónimos Palomar, Palomares, Palomarejos... Algunos de ellos presuntamente pueden representar torres que en origen tuvieron funciones defensivas y después fueron utilizadas para la crianza de palomas, ave muy común en los montes y dehesas de Talavera. Este doble uso ya ha sido puesto de manifiesto en otras zonas de dominio andalusí como en Levante o en la Mancha ${ }^{40}$.

Pero lo que se traduce a partir de la documentación, la toponimia y la arqueología es que estamos ante un paisaje medieval que está en vías de reconstrucción. Un paisaje que, a pesar de las injerencias y la acción destructiva del crecimiento urba-

37 M. I. PEREZ DE TUdELA y otros, Arquitectura militar castellano-leonesa. Significado histórico y Glosario (S. VI-XIII). Madrid, 1991. pp. 134 y ss.

${ }_{38}$ Ibidem, p. 135; asi aparece cuando la Crónica describe la Torre de Fortún Fortúnez

39 Crónica del Emperador Alfonso VII. Edición M. Perez Gonzalez, León, 1997, p. 172.

4) F. BeltRAN I LOPEZ, “La Torre de Mussa de Benifaió. ¿Una torre palomar árabe del siglo xi?" en Revista de Arqueologia, 233, 2000, pp. 51-53. F. Franco Sanchez, Vías y defensas andalusies en la Mancha Oriental. Alicante, 1995, p. 145. Este autor explica que en algunas fuentes árabes se encuentra la forma bury con el significado de palomar. 
nístico en lugares actualmente poblados, y las acciones agropecuarias de las últimas décadas que han eliminado vestigios de esta índole, se conservaba todavía casi intacto a mediados del siglo xIX. En el Diccionario Geográfico de Madoz se apuntaba, por ejemplo, la presencia de elementos fortificados por doquier: "...no hay cerro medianamente elevado en la parte septentrional de estas sierras donde no se conserven paredes de las atalayas, casas fuertes y torres de refugio..." ${ }^{41}$. Esta nota distintiva de un paisaje cargado de torres nos proporciona una base interpretativa perfilada por una jerarquia de elementos defensivos destinados al control del territorio. $Y$ aunque pueden corresponder a diferentes momentos cronológicos la dispersión de estas fortalezas son indicadoras de un sistema determinado de control del territorio, y una forma de articular el fomento y seguridad de núcleos poblacionales.

\section{INTENTO DE CLASIFICACIÓN DE LAS FORTALEZAS}

Vista la variedad de tipologías de fortificaciones que encontramos en el espacio geográfico objeto de estudio intentaremos articular una mínima clasificación, que no pretende en todo caso mas que servir de herramienta metodológica y una aproximación al asunto de la jerarquización cronotipológica de estos elementos:

*HUSUN: Fortalezas de origen andalusí que jalonan el valle del Tajo en la zona talaverana, y centrados en funciones de control del territorio, ocupando un primer lugar en la jerarquía de los elementos defensivos de la Marca Media, y que desde el punto de vista poblacional suponen un refugio para gentes y ganados de los campos circundantes. La esencia militar de estos emplazamientos es innegable. En nuestra zona tenemos los ejemplos de Canturias ${ }^{42}$ Castros, Espejel, Peñaflor, Alija, o Albalat, todos ellos en la línea del Tajo entre las provincias de Toledo y Cáceres ${ }^{43}$. También existian otras fortalezas similares vinculadas al control del río, como Alcolea ${ }^{44}$.

41 P. MADOz, Diccionario geográfico-estadístico-histórico de los reinos de España y sus posesiones en Ultramar. Madrid, 1845-50. Articulo "La Jara".

42 F. JIMENEZ DE GREGoRIO, “El Castillo de Canturias, la reconquista y repoblación de Alfonso $\mathrm{VI}$ en la Jara". Estudios sobre Alfonso VI y la Reconquista de Toledo. Toledo, 1988, tomo II.

43 Sobre estas fortalezas vid F. JIMÉNEZ DE GREGORIO, "Fortalezas musulmanas de la linea del Tajo" en Al-Andalus, vol. XIX, 1954, pp. 410-420. S. MARTINEZ LILLO, "Arquitectura militar de ámbito rural de la Marca Media (al-Tagr al-awsat). Antecedentes y evolución» Boletin de Arqueologia Medieval Española, $\mathrm{n} .{ }^{\circ}$ 4, 1990, pp. 135-171. S. MARTinez LILLO y L. SERRANO-PIEDECASAS, «El poblamiento andalusí en Al-Tagr al-Awsat (Marca Media). El mundo Omeya" en Castillos y territorio en Al-Andalus. Granada, 1998, pp. 71115. A. ArCaz Pozo, "Al-Balat: un enclave estratégico en la línea media del Tajo durante la reconquista (s. Xl-XII)" en Actas de las I Jornadas de Historia Medieval de Extremadura. Cáceres, 2000, pp. 85-105. Un trabajo más reciente de S. SANCHEz SANz, "Fortalezas rurales en la Marca Media: el caso del rio Tajo" en Actas del Simposio Mil anos de fortificaçoes na Peninsula lbérica e no Magreb (500-1500). Lisboa, 200, pp. 833-937.

44 Alcolea (ar. al-qulaya: el castillejo) aparece en un privilegio de 1086 (A.Catedral de Toledo, 0.2.N.1.1, perg. 830/5309) “in terre de Talabeira"; igualmente, por una lectura errónea se ha querido leer e identificarla, en el mismo documento, con una Torre del Duc dentro del alfoz talaverano (JIMENEZ DE GREGORIO, "Las Torres de Alcaudete», B.S.E.E. LIII, 1949), cuando en realidad en el documento aparecen los topónimos Turrus y Duque como lugares de otras zonas toledanas. Vid. J. A. Garcia LuJAN. Privilegios reales de la catedral de Toledo (1086-1462). Toledo, 1982, vol. II, p. 18. 
*BURY: De otro lado, y en una escala inferior dentro de esa red jerarquizada de elementos defensivos, se disponía una serie de torres islámicas - bur-localizadas en lugares de altura y con visibilidad amplia para una mejor eficacia en la defensa. Suele tratarse de pequeños recintos amurallados en los que encontramos incluso torres 0 atalayas como unidades particularizadas. Dentro de esta tipología podríamos incluir El Marco (Villar del Pedroso, Cáceres) ${ }^{45}$, Posada del Rey (Valdelacasa de Tajo, Cáceres) y El Castillejo (Navalmoralejo, Toledo) ${ }^{46}$.

"ATALAYAS: Un tipo muy determinado de torre vigía, como las almenaras que jalonan los territorios fronterizos de la Marca Media ${ }^{47}$. Dada su buena función desde el punto de vista estrategico-militar, a pesar de tener, en muchos casos un origen islámico, son reaprovechadas en la etapa cristiana para idénticos fines. Aunque puede haber una variedad en sus plantas, predominan las atalayas de planta circular. Debemos tener en cuenta que su situación generalmente es en cerros y lugares de gran altura con unas amplias perspectivas de visibilidad. Algunas bury y turris pueden integrar en su cometido similares funciones a las atalayas. En la zona que estudiamos podemos considerar dentro de este grupo las de El Casar de Talavera, Segurilla, Cerro de San Vicente, la desaparecida de Cardiel de los Montes o Atalaya de Torrejón en Sotillo de las Palomas ${ }^{48}$ que tienen un origen andalusí, y añadimos otras que parecen ser más tardias, como la de Mejorada ${ }^{49}$.

${ }^{*}$ CASTILLOS: generalmente asociados a los procesos de repoblación cristiana, si bien en algunos casos pueden tener origenes islámicos. Dentro del organigrama juegan un papel de refuerzo en el sistema defensivo de la organización territorial. A partir del siglo xIII algunos de ellos constituirían además los símbolos del poder nobiliario en la zona, como es el caso de Oropesa, Mejorada, Villalba ${ }^{50}$, San Roman ${ }^{51}$, Santiesteban en San Martin de Pusa ${ }^{52}$, etc.

45 J. Jimenez GadeA, "La "atalaya" del Castillo del Marco (Villar del Pedroso, Cáceres)" en Actas del IV Congreso de Arqueologia Medieval Española. Alicante, 1993, tomo II, pp. 373-379.

4i Martinez y Serrano-Piedecasas, op. cit, pp. 108-109. Jimenez de Gregorio, "Castillos, torres y fortalezas de la Jara», B.A.E.A.C. 16, 1956, p. 184, la denomina Torre de Navalmoral, a partir de la referencia que de ella se hace en las Relaciones de Felipe II: «...en frente de una atalaya que hubo en tiem. po de moros en unos riscos altos, de la cual hoy dia hay mucha parte en pie" (Navalmoral y Fuentelapio).

¿ 7 . CABallero y A. MATEO, "El grupo de atalayas de la sierra de Madrid" en Madrid del siglo ix al $x t$. Madrid, 1990. pp. 65-78. R. AzuAR Ruiz, "Atalayas, almenaras y rábitas» en Al-Andalus y el Mediterráneo, Madrid, 1995, pp. 67-76.

${ }^{48}$ Sobre la primera de El Casar, hay documentación del siglo xII que la denomina "Torre del Almendral", y luego en el siglo XV "Torre del Alcabalaje", situada en el cerro Malojo (vid. C. PACHECO JIMENEZ (coord.), Mejorada: historia de una villa de señorio. Talavera, 2000, $\rho$. 45.) Para el resto de atalayas islámicas vid. MARTinez LILLO, "Arquitectura militar de ámbito rural de la Marca Media...»; sobre la Atalaya de Sotillo, J. A. Chavarria Vargas, “El Valle del Tietar en la Marca Media de Al-Andalus (Al-Tagr Al-Awsat)" en Trasierra, n. ${ }^{\circ}$ 2, 1997, pp. 95-112.

${ }^{4}$ Pacheco Jimenez, Mejorada..., p. 33.

50 B. Maquedano, "Mejorada y Villalba: dos castillos señoriales en el siglo xvl» en Castillos de España, 108, 1997, pp. 35-46. C. PACHECO JIMENEZ (coord.). Mejorada... Sobre Villalba vid. además el articulo incluido en las actas de este congreso.

${ }^{51}$ El castillo y torre de San Roman estaban ya arruinados en el siglo xvl: "... Hay en esta villa un castillo antiguo el cual esta caido o derribado, no tiene enhiesto mas que las paredes las cuales son de mamposteria de piedra y cal." (Relaciones de Felipe II, "San Roman")

52 Acerca del castillo de Santiesteban las Relaciones de Felipe $1 / 10$ incluyen dentro de los elementos fortificados de la zona: "Y a media legua de esta villa junto al rio Pusa yendo desde esta villa entre el 
*TURRES: Bajo esta denominación tenemos diferentes realidades constructivas. Desde torres cristianas aisladas que pueden aprovechar estructuras anteriores andalusies, hasta las que se erigen a modo de atalayas en lugares prominentes. Sin embargo, hacemos un hincapié especial en aquellos elementos fortificados que asumen funciones de refugio, control y vigilancia del territorio circundante, y que pueden servir de residencia en ciertos momentos, y además asumen un papel focalizador para la repoblación y la creación de caseríos en torno ellas, sobre todo a partir del siglo XIII.

Existe además un tipo de turris que forma parte de antiguas alquerías y almunias hispanomusulmanas que son readaptadas en época cristiana.

\section{LAS TURRES EN EL ÁREA TALAVERANA DESDE LAS APORTACIONES DOCUMENTALES Y ARQUEOLÓGICAS}

A continuación pasaremos a relacionar una serie de casos de turris y elementos fortificados que hemos registrado tanto en la toponimia, como en las fuentes documentales. Algunas de ellas subsisten y de otras muchas solo tenemos referencias textuales. Advertimos que a pesar de lo difuso del término turris hemos incluido en esta lista aquellos ejemplos donde las características tanto constructivas como geográficas y estratégicas se cumplen para considerarlas como tales:

- ALCOBA, El:

Finca, musallá?, almunia y torre ${ }^{53}$, antigua villa romana. En término de Talavera de la Nueva.

Según la interpretación de Pavón Maldonado ${ }^{54}$ estaríamos ante un caso de enclave fuertemente romanizado, aprovechado por visigodos, musulmanes y cristianos. La idea de una almunia con algún oratorio o musallá ${ }^{55}$ no carece de lógica si tenemos en cuenta que posteriormente se edificó allí una ermita, conocida en el siglo Xvi como Nuestra Señora de la Alcoba, posiblemente en un intento de cristianización de un lugar de culto musulmán. La existencia de una torre vecina en el lu-

norte y el poniente están unas señales de edificios antiguos, en los cuales se halló una piedra cuadrada con una labor como a manera de cruces de la forma del habito de San Juan... y en la dicha dehesa de Valdepusa hay algunas señales de edificios antiguos como es un a manera de castillo que llaman castillo de Santisteban". Por otra parte, otra fuente más antigua, Anales Toledanos II, (edición de J. PORRES, Toledo, 1993, p. 99) señala que en el año 1117 hubo una "arrancada sobre los de Toledo en Sant Esteban $X X I I I$ dias de Julio. Era MCLV'. Porres cree es más probable que se trate del castillo de Santiesteban, en la orilla izquierda del rio Pusa, que se cataloga como probable obra cristiana del siglo Xil, defensiva contra un ataque almorávide procedente de los Montes de Toledo.

53 PACHECO JIMENEZ, "Almunias medievales...", p. 378

54 B. PAVÓN MALDONADO, "El topónimo de origen árabe "Alcoba" (Talavera) en Superposición de las culturas ibérica, romana, goda y árabe en la provincia de Toledo en Al-Andalus, XIV, 1977, pp. 409-417.

55 La musallá: oratorios al aire libre con un muro donde ubicar el mihrab o nicho provisional, podría explicar la al-qubba. TORRES BALBAS, "Musallà y "Sari'a" en las ciudades hispanomusulmanas" en Al-Andalus, XIII, 1948, pp. 167-180. 
gar conocido como Torrejón, nos sugiere una identificación con un elemento fortificado que podría remontarse a época romana, como torre defensiva de la villa allí existente. Por su parte, Zozaya recuerda que las más primitivas torres de planta cuadrada emirales estaban rematadas con bóveda lo que da lugar en la toponimia romance a nombres como qubba: alcoba, alcubilla, etc. ${ }^{56}$

La etimología del árabe al-qubba: "la bóveda, la cúpula" suscita otras interpretaciones como aljibe o depósito ${ }^{57}$ o Musallá (oratorio). Entre as referencias documentales más antiguas que tenemos figuran las siguientes:

- 1203: escritura de venta de una «viña en el Pago de Baric, junto al camino de Alcoba" ${ }^{58}$.

- 1346: Se recoge en una escritura relacionadas con las huertas, casas y torre de Torrejón de la Alcoba:

"...las casas e la huerta e las heredades de Alcoba que disen de la Torre..." ${ }^{59}$.

- 1420: Escritura de donación hecha por Alfonso Fernández de Caballero e Isabel Gutiérrez, su mujer, de las heredades de Torrejón de la Alcoba y otra ${ }^{60}$.

\section{- ALDAHUÍ}

Término de Alberche del Caudillo. Entre Torrejón y Alberche.

La proximidad de la finca de Torrejón de la Alcoba, con la que lindaba, según los documentos del siglo XIV, vinculan este topónimo a elementos también fortificados en la vega talaverana. Aparece con distintas formas como Alfahuí, Arsaguy, Alfarahui, Adaralahuí: A(L)DAR AL-AHUI> posible etimol.: El Dar del Judío: La tierra o casa del judío ${ }^{61}$ : DAR: Casa fuerte, en el sentido de almunia-torre ${ }^{62}$. Ver tambien Torrejon de la Alcoba.

\section{- ATALAYUELAS, Las}

En término de Velada, al oeste de la población en el Camino y finca El Barrero, y próximo a Cerro Dávila. Mantiene restos de construcción medieval, presunto recinto fortificado (qasr o similar). Aunque hay que relacionar este lugar con el proceso de repoblación por parte del concejo de Avila, mediante la donación que se

56 F. Saez, A. Malalana y S. Martinez, "Poblamiento y red viaria en la Marca Media: Un comienzo de aproximación (ss. VIII-x)" en Actas del II Congreso de Arqueologia Peninsular. Tomo IV: Arqueologia romana y medieval. Madrid, 1999, p. 549. J. ZOZAYA, "Las fortificaciones de al-Andalus" Al-Andalus. Las artes islámicas en España. Madrid, 1992, p. 65.

57 Gomez MenOR, op. cit., p. 129.

58 A. Gonzalez Palencia, Los mozárabes de Toledo en los siglos xil y xill. Madrid, (1926-30), doc. 327.

59 A.H.N., Nobleza, Frias: Leg 572.

60 A. Colegiata de Talavera, Caja 145, n. 24. C. PACHECO JiMÉNEZ, Estudio histórico-arqueológico de la finca de la Alcoba (Talavera de la Reina). Talavera, 1989. Inédito.

6: GOMEZ MENOR, op. cit., 129.

62 PACHECO, "Almunias...", p. 378 
hizo en 1276 a Velasco Velázquez del lugar de Velada ${ }^{63}$, de este sector de la zona talavera, pensamos que pudo existir una antigua casa-fuerte o qasr aprovechada en el siglo XIII como bastión en el proceso repoblador.

Otro lugar denominado también como Las Atalayuelas en el siglo XVIII se localizaba en el término de Chozas - actualmente de Calera y Chozas, y posiblemente en la dehesa de ésta última ${ }^{64}$.

\section{- AVIONES, LOS}

Cerca de Alariche?, junto al Tajo, en el término de Calera y Chozas.

Aparece con una etimologia de "Brj Bn Ywns": Bury ab Yunus: Torre-almunia ben Yunus ${ }^{65}$. Se menciona ya en un documento de 1216: Don Antolín vende al fraile don Juan representante del $\mathrm{M}^{\circ}$ de San Clemente de Toledo, una noria, su plana y canales en el río Tajo, en el pago Los Aviones ${ }^{66}$.

La lectura de González Palencia y Ferrando Frutos apareciendo el término burjo bur nos sugiere un nuevo caso de almunia-torre o casa de campo fortificada, interpretada por el habla mozárabe con esa fórmula incluyendo el antropónimo.

\section{- BRIUGUILLA}

Actualmente corresponde con el topónimo Burguilla, cuyo origen etimológico puede estar en bury- al igual que en el caso de Brujel (Burjel: Borgel), ambos relativos a turris de origen islámico. El topónimo se encuentra hasta tres veces en el MTN, Hoja 653-IV, en la carretera entre Villar del Pedroso y Valdelacasa. Aparece ya mencionado el paraje en el deslinde de 1485 de la dehesa de Torriquillo en la jara cacereña: "...e dende va a dar al camino que va desde el Torriquillo a Briuguilla...» 67 .

\section{- BRUGEL}

Antiguo despoblado cerca del municipio de Cazalegas.

La etimología Brugel o Burgel, según aparece en documentación moderna, tiene su raíz, como otros tantos topónimos similares, en bur o burj; y su vinculación con el proceso repoblador parece evidente, pues sirve de elemento de control del territorio pero también de aglutinante para la formación de un caserío que llega a convertirse en aldea y lugar de la tierra de Talavera. En las Relaciones de Felipe II decian los informantes en 1576 que «el lugar es muy antiguo porque el edificio de

63 J. I. MORENO NUNEZ, “Algunas consideraciones y documentos sobre el régimen señorial en el transito a la Baja Edad Media» en Anuario de Estudios Medievales, 16, 1986, pp. 107-126.

64 A. MARTINez Cuesta, «Talavera de la Reina y los agustinos recoletos» en Recollectic, 14, 1991, pp. 5-171.

65 Ferrando Frutos, op. cit.

66 Gonzalez Palencia, op. cit., doc. 432

$67 \mathrm{AMT}^{\mathrm{a}}$, Jurisdicción. Sig. 1.007. 
la capilla de la iglesia es edificio de romanos...". Realmente en el entorno de este despoblado se localizan restos de alguna villa romana; pero posiblemente el embrión del caserío estaría en una turris enclavada en esta parte del valle de Alberche, en torno a la cual debió de crecer la aldea.

\section{- CALAHORRA}

En la zona norte de la Sierra de San Vicente, en el termino de Sartajada, existe el cerro Carrahola o Carrabola forma desviada de Calahorra (ar. qalahurra), que en este caso parece cumplir funciones de atalaya frente a otras acepciones ${ }^{68}$. En El Libro de la Montería se menciona "et la otra desde Torinas por las veredas que entran del Iglejuela hasta Navapalaciana. Et son las armadas a una en las Canadiellas que entre la Calahorra et la Guijosa” ${ }^{69}$.

\section{- CASAR, EI}

Antiguo pueblo, y barrio de Talavera de la Reina desde mediados del siglo xIX, situado al oeste en la carretera N-V hacia Extremadura.

Una presunta etimología de Casar < qasr (pl. qusur) > qasar ${ }^{70}$, puede relacionarse con el sentido de casa fortificada con funciones de parador o fonda. Su situación, junto al camino real a Extremadura y antigua vía romana de Mérida a Toledo, refuerza esta hipótesis.

Franco Sánchez explica casos de -Qasr (al-qasr. Alcázar, almunia/albergue fortificado, con torre (hisn o bury) como Alcàcer (Valencia) casona-torre a la salida de Valencia ${ }^{71}$

De admitir esta interpretación que reseña Franco Sánchez, estaríamos ante una posible dualidad de funciones de este caserío: almunia-torre (fortificada) y manzil o venta en el ámbito de zonas más o menos despobladas pero próximas a una ciudad. Hay que tener en cuanta la proximidad de la Atalaya del Casar ${ }^{72}$, ubicada en el cerro Malojo, y conocida en documentos del siglo xill como «Torre del Almendral» 73 .

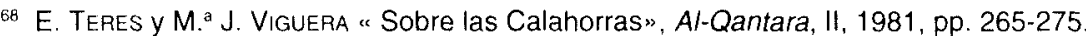

69 AlFonso XI, Libro de la Montería. Edición de M. ${ }^{a}$ I. Montoya Ramírez. Granada, 1992, pp.430 y 436. J. A. ChavarRIA, Toponimia del Alto Tietar (Avila/Toledo) en el Libro de la Montería de Alfonso XI. Madrid, 1999

70 Ferrando frutos, op. cit., p. 242.

71 Franco Sanchez, op. cit., p. 90.

72 Sobre esta atalaya islámica-cristiana vid. S. MARTiNEz LiLLo, "Arquitectura militar de ámbito rural de la Marca Media (al-Tagr al-awsaf). Antecedentes y evolución" Boletín de Arqueologia Medieval Española, $n^{\circ} 4,1990$, pp. 135-171

73 Asi aparece en el deslinde entre el término de Talavera y el del nuevo señorio de Mejorada que crea Sancho IV en 1288, en la figura de Juan Garcia de Toledo (A.H.N. Nobleza, Frías, leg. 508, n. ${ }^{\circ}$ ). Vid. A. FaAnco SILVA, "La fundación de pueblas en tierras situadas al noroeste del Reino de Toledo" en Historia, Instituciones, Documentos. Sevilla, 1990, pp. 31-53. PACHECO JIMENEZ, C. y otros, Mejorada... pp. 57 y 58. 


\section{- HORNILLOS}

Es el nombre de una heredad que tenía a censo el licenciado Jofre de Loaisa en el siglo $x v$, y que lindaba con la ribera del Tajo. En ella se encontraba una torre $^{74}$.

\section{- MONTEMAYOR}

Aldea con torre en el Jébalo en el sector de la Jara. Montemayor es un caso de complejo rural en el que la turris puedo jugar un papel determinante en la defensa del espacio circundante. Referencias documentales de 1332 os hablan de: «...la metad que yo he en el aldea que disen Monte Mayor que es en Valdexébalo, termino de Talavera, asi en las casas, en el cortijo, en la torre como en la viña, en todo el heredamiento... " ${ }^{75}$; y también se menciona en una sentencia de $1492^{76}$.

\section{- NAVAMORCUENDE}

Este municipio serrano, situado al norte de la Sierra de San Vicente, y próximo a Sartajada, es uno de los lugares de creación a partir de la repoblación del concejo abulense en el siglo $x{ }^{11}{ }^{77}$. Dentro del recinto del palacio de los marqueses existe una construcción rectangular que parece ser una estructura torreada, con un aparejo muy similar a los de fortalezas de repoblación ${ }^{78}$.

\section{- PALOMARES}

Cerca de Alariche, término de Calera y Chozas. Hoy Casa de Palomares.

El topónimo Palomar > Palomares > Palomarejos : puede estar relacionado con la presencia de antiguas torres de control del territorio rural, que fueron reinterpretadas en época castellana como tales por su similitud, incluso algunas de ellas debieron ser reaprovechadas para este fin.

La vinculación entre las turres y los palomares parece estar demostrada en algunos casos como hemos visto más arriba. En la documentación mozárabe aparece la forma abraj (de burj= torre) alhaman: palomares o torres palomares ${ }^{79}$.

74 E. SOlano, La Orden de Calatrava en el siglo xv. Los señorios castellanos de la Orden al fin de la Edad Media. Sevilla, 1978. Vid. "Encomienda de Talavera".

75 A. Municipal de Talavera, Documentos del Monasterio de San Clemente de Toledo, caja 1, n. 13.

76 Gomez Menor, op. cit., p. 141

77 La creación del señorio de Navamorcuende y Cardiel tuvo lugar en 1276, en una parte del concejo de Avila, quien concede el 1 de noviembre de ese año a Blasco Ximénez el señorío de estos territorios. Vid. Moreno Nunez, Avila y su tierra... , p. 59. El establecimiento de población en el mismo debió de consolidarse ya a principios del siglo xıv, según indicios arqueológicos funerarios que exponemos en nuestro trabajo "Arqueología medieval en la Sierra de San Vicente: Datos sobre una necrópolis de Navamorcuende", Cuadernos Abulenses, 31, 2002, pp. 101-116.

78 Esta estructura y otros restos de complejo palaciego están siendo estudiados en una intervención arqueológica dirigida por Domingo Portela. Esperemos en un futuro que los datos arqueológicos puedan arrojar más luz sobre este asunto.

79 González Palencla, op. cit, doc. 596. 
Otro Palomares existia en el Horcajo, entre Cochino y la Espiga, se menciona en Sentencias del siglo Xv, como propiedades de la iglesia Colegial de Talavera ${ }^{80}$. Topónimos similares como Palomarejos ${ }^{81}$ pueden haber seguido el mismo proceso de atribución funcional sobre restos de estructuras defensivas de la campiña y la huerta talaverana.

\section{- TORRALBA}

Actual municipio próximo a Oropesa, tiene su origen en una antigua turris que en el siglo xvi estaba en estado ruinoso: «el pueblo de Torralba...está fundado en llano y que no tiene ni cerca ni muralla ninguna, mas un torreón muy viejo y caido la mayor parte de él que es cal y canto mal labrado..." "22. Como parte del Campo de Arañuelo, Torralba pertenecía al concejo abulense, y su proceso repoblador a partir del reinado de Alfonso X permitirá la localización de poblamiento en torno a esta torre. En sus inmediaciones se conserva el topónimo Atalaya.

\section{- TORRALBILLA O TORREALBILLA}

Dentro del termino de Villar del Pedroso, en la provincia de Cáceres, pero a corta distancia del Puente del Arzobispo. Hay referencias documentales del siglo XIII a una torre que después fue ocupada por una casa de labor que actualmente subsiste ${ }^{83}$. Su situación, al lado del Tajo, constituye un factor determinante como turris de vigilancia del paso ganadero desde al menos época islámica. A la vez se relaciona con bury como La Oliva, o El Castillejo y el hisn de Castros.

\section{- TORRE}

Bajo este topónimo o derivados se localizan numerosos casos en la zona entre los que cabe destacar por su aportación a la arqueología ${ }^{84}$ los siguientes: Carril de la Torralba (La Pueblanueva). Camino de Navalatorre, Atalaya de Torrejón ( Sotillo de las Palomas). Arroyo de Torrejón, Torrejón. (Los Cerralbos). Atalaya (Otero).Torrejón (Malpica).La Torre (Los Navalucillos). Senda de la Atalaya (El Torrico). Valdetorres (Valdeverdeja). Torlamora (Mohedas). La Torre (Belvís de la Jara): antigua alquería documentada ya en el siglo XIV.

80 Gomez Menor, p. 143. También en un deslinde de los abrevaderos del Horcajo de 1434 (Archivo Municipal de Talavera. Pleitos II) se menciona un "soto de Palomares" cerca de otros enclaves como Alfondiga y la Torrecilla.

${ }^{81}$ En la comarca de Talavera tenemos al menos dos lugares con este nombre, un Palomarejos, a 1 $\mathrm{km}$.al este de Talavera y junto al antiguo Camino Real - hoy Nacional $V$ - , que aparece ya registrado en documentación bajomedieval. Otro Palomarejos en el término de Calera y Chozas, finca situada cerca de la Casa de Postas, y lindando por el norte con la autovía de Extremadura. Además un Palomar se localiza en un paraje situado entre la Casa las Córdobas y Valdelacruz.

82 Relaciones de Felipe I/, "Torralba" (Madrid, 1951). Lo recoge J. I. MORENo NuÑEz, "Fortalezas en el extremo meridional del alfoz de Avila (Notas sobre su pasado medieval)", Castilos de España, 23 1985, pp. 31-38.

"3 JIMENEZ DE GREgorio, “Castillos, torres...", p. 181.

${ }_{34} \mathrm{M}$. DE LA VEGA, "La toponimia como elemento de apoyo en la investigación histórico-arqueológica en la zona occidental de la provincia de Toledo" en Cuaderna, 7-8, 1999-2000, pp. 38-53. 


\section{- TORRE ALFONDEGA}

Término de Calera; puede corresponder con la casa de Baldosadero.

En escritos mozárabes aparece como albur min alfuntiqa: la torre de la alfondega (funduq: posada o venta).

- 1177: Transacción de 3 tierras entre mozárabes; una de ellas «en la Torre de Alfondega hasta la Torre...» ${ }^{85}$. Esta segunda Torre pudiera tratarse de la Torre del Conejo próxima a ésta (posada o venta).

En la delimitación del término de Avila con Talavera, realizada por Alfonso VII en $1152^{86}$, se recoge el topónimo Vallefonsados, que puede relacionarse con el actual Baldosadero. Otro enclave con la denominación de Alfondega existía en el Horcajo, en el término de Cazalegas, próximo al valle del Bajo Alberche ${ }^{87}$, junto a otro paraje conocido como La Torrecilla.

\section{- TORREBELLA}

Con esta denominación aparece una aldea que es objeto de donación por parte de Alfonso VII a Domingo Pérez y a otros vecinos mozárabes ${ }^{88}$, sin que podamos saber su ubicación exacta.

\section{- TORRECILLA}

Bajo esta denominación se recogen numerosos topónimos en toda la geografía peninsular; en la zona de Talavera también hay varios registrados tanto en la toponimia actual como en las fuentes documentales, que pasamos a enumerar:

1. En la parte oeste del término de Calera y Chozas, cerca del primitivo despoblado de Zurrasbotas ${ }^{89}$, existe un paraje que conserva el topónimo Torrecilla. Posiblemente esté vinculado al proceso de poblamiento plenomedieval de este sector, y en conexión topográfica con el antiguo castillo o fortaleza de Al-qulaya (Alcolea de Tajo).

85 Gonzalez Palencia, op. cit., documento 132.

86 Gomez MEnOR, op. cit.. pp. 53-54, documento 1: Privilegio de Alfonso VIl delimitando las tierras de los concejos de Avila y Talavera, septiembre de 1152. A.M. Tª, Privilegios, legajo 1.

${ }_{87}$ En el documento figura el siguiente título: "Señalamiento hecho por los señores justizia y rejimiento de esta villa de Talabera de los abrebaderos para los ganados de los vezinos del el Horcajo, de su jurisdizión, que empieza desde el Zorrizo, asta el Soto de Palomares; y desde alli asta dar en el Soto de Cochino, y desde aqui hasta dar en el soto de Alfondiga $=Y$ desde aqui el camino adelante de esta villa, asta dar en la Puente y río de Alberche; y desde aqui asta dar en el soto de Corralejo, y desde aquí asta dar en las viñas de Cazalegas y asta dar en el soto de Torrezilla, guardando sotos y dehesas boyales. $y$ panes y binas, y ponen ziertas penas para que esto se obserbe de aqui adelante. Su fecha en 19 de maio, año de 1434" A.M.T. ${ }^{\mathrm{a}}$. Pleitos II. 1434.

${ }_{B 8}$ Existen varias copias de este documento fechado el 22 de septiembre de 1155 en Talavera, entre ellas las del A.H.N., Códices, Tumbo de la Orden de Calatrava, sig. 833 B, fols. 181-182. Citado por RoDRIGUEZ-PICAVEA, op. cit, p. 152, doc. 20.

¿9 La heredad de Zurrasbotas pertenecía a finales del siglo $x \vee$ a la familia talaverana Meneses y en 1418 es citada en una Sentencia del Deán Riaza. Gómez MENOR, op. cit. 
2. Otra Torrecilla, como ya hemos apuntado, se encontraba en el Horcajo, próxima a Cazalegas «...y desde aqui asta dar en las viñas de Cazalegas y asta dar en el soto de Torrezilla..." ${ }^{90}$.

3. Torrecilla de Alcaudete o de la Jara, antiguamente lugar de la tierra de Talavera, tiene su origen igualmente en una de las torres jareñas que toman cierto protagonismo durante la repoblación a partir del siglo XIII. En las Relaciones de Felipe // recogen la tradición de que se llamaba así «...porque oyeron decir que estaba antiguamente una torrecilla dentro de este pueblo..."

4. Torrecilla, cerca de Navamorcuende en la parte norte de la Sierra de San Vicente. Es mencionada en el Libro de Montería de Alfonso XI: "Et son las vocerias, la una desde que entra en el camino que va de Navamorcuende, et entra en la Xara por somos de la Torreciella hasta Torinas" 91.

5. Otra Torrecilla existia como heredad próxima a Talavera, en las estribaciones del Berrocal, y próxima a la dehesa de Valdefuentes. Es citada en sentencias de principios del siglo Xv, y en un documento de 1739 se mantiene todavía el topónimo: "...sigue la falda del cerro de las Aguardas hasta el camino de Torrecilla entre Segurilla y Talavera...la Portiña arriba hasta el camino de Torrecilla» ${ }^{92}$

6. Torrecilla de Juan Martín, recogida también en la obra del rey Alfonso: "La Xara del Algibejo et la Cabeza de la Torreziella de Johan Martín es todo un monte, et es bueno de puerco en ynuierno, et a vezes ay osso..." 93 . Se localiza, posiblemente, en la zona de la jara cacereña.

\section{- TORRE DE AZUTAN}

En realidad, Borge al-Sultan, que Jiménez de Gregorio relaciona con los restos del paraje conocido como Los Castillos junto al Tajo, en Azután ${ }^{94}$ y actualmente desaparecidos. La turris/bur fue entregada en 1135 al magnate mozárabe Miguel Midiz, según privilegio de Alfonso VII ${ }^{95}$.

\section{- TORRE DE BEN-CACHÓN o Mecachón}

Término de Membrillo-Las Herencias.

Documento del siglo xv. Las Relaciones de Felipe .II de Las Herencias: "y otra Dehesa llamada Ben-Cachón... y tiene una torre muy alta hecha de ladrillos y es cosa muy antigua y el edificio della es muy antiguo....(1578).

90 Archivo Municipal de Talavera. Pleitos II. 1434.

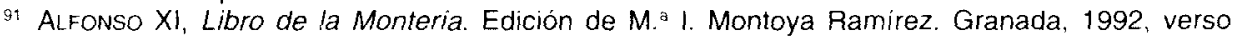
4.747, p. 436.

92 A. Colegiata de Talavera, Desinde entre Talavera y Mejorada. 1739. Caja 336, n. 24.

as Libro de la Monteria, p. 572

94 JIMENEZ DE GREgorio, "Castillos, torres...", p. 178

95 B.N. ms. 13093, fol. 81. 
El topónimo resulta elocuente; la tradición de asentamientos bereberes en el alfoz de Talavera justifica la existencia de este tipo de nombres asociados a enclaves fortificados de carácter agrario ${ }^{96}$.

También en el término de Las Herencias, cerca de la actual finca de Mecachón, pero más al este, se encuentra el arroyo de la Aceitunilla ${ }^{97}$, que discurre de sur a norte y la labranza del mismo nombre. En sus proximidades se mantiene el topónimo El Torreoncillo, presumiblemente atribuido a alguna construcción similar a la anterior. Jiménez de Gregorio considera que puede identificarse con una construcción cuadrangular de $1,50 \mathrm{~m}$. de lado de mamposteria y cal, y con arranque de bóveda, que existe a dos kilómetros del caserío ${ }^{98}$.

\section{- TORRE DE CASTELLANOS o Casa de la Torre}

En término de Alcaudete de la Jara. Está situada en un cerro junto al valle del Jébalo desde el cual domina toda la amplia vega de este río y los montes meridionales de Alcaudete y Belvís. Está dentro de la antigua dehesa de Castellanos, que pertenecía desde finales del siglo XIV al monasterio jerónimo de Santa Catalina de Talavera, por donación de la familia Calderón.

Se trata de una construcción rectangular de $10,90 \times 7,10 \mathrm{~m}$. y en el interior consta de una amplia cámara con bóveda de arista, y escalera que conducía a las dos plantas superiores. Actualmente la parte superior ha sido reparada y la cubierta remozada. Tenía en la fachada sur un hueco, ahora tabicado, que serviría para matacán ${ }^{99}$. Los muros tienen una base con hormigonado de cantos rodados hasta media altura, y encima mamposteria encintada con esquinales de ladrillo, similares a las obras mudéjares del siglo XIII-XIV.

Esta puede ser el caso de una torre asociada a elementos de la oligarquía que utilizan estas torres como expresión feudal al tiempo de servir de fortaleza y protección de sus dominios.

Cerca de esta turris, Jiménez de Gregorio asegura haber localizado otra torrecilla en la vecina labranza de El Carpio ${ }^{100}$, también en el valle bajo del Jébalo y hoy junto al pantano de Azután.

96 Jimenez de Gregorio, "Castillos, torres y fortalezas de la Jara» en Boletin de la Asociación Española de Amigos de los Castillos, 16, 1956, pp. 173-189.

97 Una aldea de Aceituna se recoge en una escritura de 1178 de la Orden de Calatrava (A.H.N., Ordenes Militares. Registro de escrituras de la Orden de Calatrava, I, sig. $1341 \mathrm{c}$, fol. 63.).

98 JIMENEZ DE GREGORio, "Las Torres de Alcaudete» en Boletín de la Sociedad Española de Excursiones, t. LIII, 1949, p. 3.

99 Según el testimonio de Jiménez de Gregorio que la conoció antes de su reforma. Vid. su obra "Castillos, torres...", p. 182. Tenia hasta hace unos años dos edificaciones adosadas por el muro oeste y fachada sur, lo que explica la concentración de material de derribo circundante.

100 F. JIMENEZ DE GREGORIO, "E| Castillo de Canturias, la reconquista y repoblación de Alfonso VI en la Jara" en Estudios sobre Alfonso VI y la Reconquista de Toledo. Toledo, 1988, t. III, p. 342. 
- TORRE DE DOÑA LAZARENA: Casa de la Torre

Término de Calera y Chozas, más al oeste de las anteriores, pero en el entorno del antiguo camino hacia Extremadura.

Parece tratarse de un ejemplo de casa-torre con antropónimo: en la documentación mozárabe aparece doña Nazarena ${ }^{101}$. Se vislumbra una función de torre aprovechada en el proceso repoblador.

\section{- TORRE DE DOÑA MARÍA}

Lleva este nombre un pago del término de Talavera: «...vendemos una vinnea que habemus sub dominio Talaveris in pago que disen de la Torre de doña Maria..." (1209) ${ }^{102}$. Desconocemos su ubicación o si se trata de otra denominación diferente de las ya conocidas.

\section{- TORRE DE FORTÚN FORTÚNEZ (Garciotún?)}

Esta famosa torre ha suscitado diversidad de opiniones de identificación y localización. La referencia textual que tenemos pertenece a la Crónica de la población de Avila: "E en este tiempo de Avila contra los moros non avia pueblo de cristianos, sino no es una torre que es en las Ferrerias. E teniala Fortún Fortúnez, cavallero de Avila, e ansi la dizen oy la torre de Fortún Fortúnez" ${ }^{103}$. Moreno Núñez considera que se trata del enclave de Garciotún o Garci Fortún, en la parte oriental de la Sierra de San Vicente ${ }^{104}$. Otros autores como Tejero Robledo ${ }^{105}$ y Martín García ${ }^{106}$ la localizan entre Mombeltrán (Colmenar de las Ferrerias) y Santa Cruz del Valle en la Torre en lo que fue luego convento de la Torre en el siglo xvi. Por su parte Angel Barrios la supone en el sitio de Torre de Miguel Martín, entre la sierra de Galayos y el Tiétar.

\section{- TORRE DE MIGUEL MARTIN}

Con este nombre aparece uno de los enclaves poblados que a mediados del siglo xIII se registran en un documento del obispado de Avila ${ }^{107}$. Entre éstos figuran además Bayuela, Garcifortún, Aldea del Obispo y San Román, todos ellos en nuestra Sierra de San Vicente. Aunque se acepta que su ubicación seria el entorno del Valle del Tiétar, por nuestra proponemos una posible localización en las proximidades del pueblo toledano El Castillo de Bayuela, donde en su sector occidental del término discurre el Arroyo Martín y existe un pago lla-

101 Gonzalez Palencia, op. cit., doc. 290; Ferrando Frutos, op. cit., p. 226

102 A. Municipal de Talavera, Documentos del Monasterio de San Clemente de Toledo, caja 1, n. 3.

103 Crónica de la población de Avila. Valencia, 1966, p. 27.

10.4 Moreno Nunez, Avila y su tierra...p. 61-62.

105 Mombeltrán. Historia de una villa señorial. Madrid, 1973, p. 13.

ing Martin Garcia, G., Mombeltrán en su historia (ss. XIII-XIX) Avila, 1997, p. 52

107 Carta del cardenal Gil Torres al obispo y Cabildo catedralicio (1250), publicada por J. GONZALEZ, "La Extremadura castellana al mediar el siglo xilı" en Hispania, n. ${ }^{\circ}$ 127, 1974, p. 416. 
mado la Torre ${ }^{108}$ - hidrotopónimo que puede acunar una herencia del topónimo y de esta antigua torre. Igualmente se cita en el documento de 1250 las Torres del Fundo, que dada la proximidad al sector del Tiétar, se pueden identificar con el despoblado de Las Torres, en término de Gavilanes ${ }^{109}$.

\section{- TORRE DE SAN MARTIN DE PUSA}

Una vez mas las Relaciones filipinas se hacen eco de la existencia de una torre dentro del caserio, formando parte del complejo palaciego: «... a la una esquina de esta casa habia una torre de piedra tosca y cal que era una torre muy antigua la qual se blanqueo y se quedo en la dicha casa..." ${ }^{110}$. La creación del señorío de Valdepusa en el siglo XIV ${ }^{111}$ supuso la atracción de pobladores que en torno a esa antigua torre empezaron a construir casas. Sin embargo, dentro del término de San Martín tenemos otros dos elementos de gran interés desde el punto de vista de las fortificaciones: el castillo de Santiesteban y la llamada Venta de Mozárabes, una casa-fuerte de apoyo a la repoblación ${ }^{112}$.

\section{- toRRE O ATALAYUELA DEL CONEJO: Casa de Atalayuela}

Término de Calera y Chozas. Antiguamente mantenía el nombre de Venta del Conejo, por un establecimiento destinado al hospedaje. Se situaba en las proximidades de la encrucijada del cordel o cañada ganadera con el Camino Real de Extremadura. En sus cercanías se mantienen los topónimos de La Talayuela y La Torre.

108 G. Martinez Diez, Las comunidades de Villa y Tierra de la Extremadura castellana. Madrid, 1983, p. 617

109 J. Chavarria y J. M. Gonzalez, "Las Torres (SS. XIII-XVIII). Evolución histórica de un despoblado en el Valle de Tiétar" en Trasierra (Boletín de la Sociedad de Estudios del Valle del Tiétar), n. ${ }^{\circ}$ 1, 1996, pp. 79-98.

110 Relaciones de Felipe II: "San Martín de Valdepusa".

111 A. PAlomeque TORRES, “Pueblas y gobiernos del señorio de Valdepusa durante los siglos XV, XVI y XVII» en Cuadernos de Historia de España, Buenos Aires, 1947

112 Los restos de este fuerte son conocidos como "Corral de la Ventilla" situada junto a un cordel ganadero que baja de los montes situados al este y se dirige hacia el oeste cruzando el rio Pusa. Se trata de un recinto cuadrangular de unos 20-23 m aprox. de lado. De muros de una anchura aprox. de $1 \mathrm{~m}$. El cuerpo de los muros es de un hormigonado de cantos rodados y trabados con un fuerte mortero de cal y arena. El aparejo exterior parece haberse perdido ofreciéndose tan sólo el núcleo de los muros. En los ángulos del recinto NE y NW se conservan parte del núcleo interior de lo que fueron unas torrecillas esquineras que reforzaban el conjunto. Todo el complejo se encuentra muy deteriorado y en alto grado de degradación; en su interior se han acumulado montones de cantos rodados procedentes de las tierras de labor circundantes (hoy dedicadas a olivares y cereal de secano). Se encuentran tanto dentro como fuera del recinto numeroso material constructivo medieval y romano (tégulas, ladrillos, tejas, etc.) y las cerámicas halladas son medievales sobre todo de cronologia mudéjar (siglo XIit-XIV) y algunas que pueden situar el asentamiento en el siglo xII. Referencia documental tenemos en las Relaciones de Felipe II (San Martín de Valdepusa): “...y otros edificios a la Madalena, que son unas paredes de tierra muy gruesas, y a la venta que dicen de Mocoraves donde hay un a manera de cerca de casa o fortaleza gruesa que todos son edificios muy arruinados y caidos y cerca de ellos hay algunas señales de edificios de casas y pozos como de anorias, de la cual no se tiene noticia del rastro de los dichos edificios antiguos para saberse que cosa haya sido y la causa por do se tiene tan poca noticia de lo que es se entiende que es el ser las poblaciones de esta tierra poco antiguas y lo demás ser cosa muy antigua y como los pobladores fueron lexos de esta tierra no tienen más noticia de la dicha". 
Su funcionalidad como torre defensiva y presunta casa de labor en torno al siglo XII-XIII pudiera vincularse al control de la vía de comunicación hacia el oeste. En el siglo xv aparece con la denominación de Torre del Conejo ${ }^{113}$

\section{- TORRE DEL CURA}

En pleno casco urbano de Alcaudete de la Jara. Es una hermosa torre asociada a los procesos de repoblación del lugar a partir del siglo XIII ${ }^{114}$. Las Relaciones de Felipe II señalan que en Alcaudete "no hay fortaleza ninguna sino es una torre antigua de piedra y cal...", y además vinculan el origen del pueblo a la existencia de la misma: "Un cazador...se habia allegado a una torrecilla como atalaya, que agora esta en el dicho lugar hecha torre en una heredad o guerta de Hernán Duque de Estrada... y habia hecho alli junto a ella una choza donde vivia, y que desde alli se habia fundado el lugar...". Otros indicios parecen apuntar a su construcción por un caballero talaverano de la familia Calderón, que en 1372 dona la dehesa de Castellanos, donde existe otra torre ya descrita, al monasterio de Santa Catalina de Talavera.

La torre ha experimentado algunos cambios y remodelaciones, distinguiéndose claramente la obra medieval de mampostería con sillares en esquinas, de la coronación con obra de ladrillo para adecuarla a vivienda ya en época moderna. Es una torre de planta cuadrangular, con una altura de unos $18 \mathrm{~m}$ y se aprecian restos de elementos como un matacán y su ladronera, y algunas saeteras. En el interior cámaras cubiertas de bóvedas apuntadas de arista, y una de ellas con chimenea ${ }^{115}$.

\section{- TORRE DEL HIERRO}

Término de Talavera de la Reina, al oeste de la población, y cerca del polígono industrial.

Hay restos arqueológicos constatados de una estructura rectangular que identificamos como la referida torre (vid. fig. ), junto a un pequeño valle del arroyo Zarzaleja que discurre de norte a sur ${ }^{116}$. En sus cercanías se recoge material romano de vicus en el borde la terraza superior del Tajo (zona de parcelas), otro vicus a $200 \mathrm{~m}$. al oeste y una presunta necrópolis tardorromana ${ }^{117}$. El recinto tiene

113 Gomez Menor, p. 147. Sentencias del Deán Riaza de 1418.

114 Jimenez DE GREGorio, "Las Torres de Alcaudete» en B.S.E.E., t. L.III (1949), p. 4 y sS.

115 Ibidem, p. 5.

116 Se ha pretendido asignar a esta estructura una funcionalidad de tumba turriforme de cronologia romana (A. MONTERRUBIO et al. "Una tumba turriforme en Torrehierro" en El Mundo Comarcal, n. 53 (23XI1-1995), pp. 28-29), hipótesis que nos parece poco probable; dada la tipologia constructiva y su relación espacial con otros enclaves de la zona de cronología medieval preferimos interpretarla como un ejemplo más torre de control y vigilancia del entorno agrario circundante del agro talaverano.

11: C. PACHECO JIMENEZ, "Caracterización de los asentamientos romanos en Talavera de la Reina: una aproximación a la organización del espacio rural romano" en Actas de las I Jornadas de Arqueologia Romana de Talavera de la Reina (noviembre 2000), en prensa. 
unas dimensiones de 7,70 x 4,10 m., con un grosor de los muros de 1,10 m. Estos están fabricados con un sólido núcleo de opus caementicium y con un revestimiento de mampostería y algún sillar con ripios para nivelación, ofreciendo un aparejo que recuerda a las obras andalusies de la zona. La tipología de torre rectangular que suele ser poco habitual en la zona, tiene un paralelo aproximado en la Torre de la Oliva ${ }^{118}$, que tiene un grosor de muros de 1,30, y unas dimensiones de $4,70 \times 8 \mathrm{~m}$.

Parece tratarse de un caso de torre asociado al control de la campiña ${ }^{119}$, y no puede descartarse el origen romano dadas las evidencias del entorno. Igualmente consideramos que asumiría funciones de torre para asegurar el proceso repoblador de la zona. El topónimo recuerda a otros similares de la región castellano-leonesa; el complemento "del Hierro" pudiera relacionarse con el concepto de torre ferrata que Pérez de Tudela interpreta bien como una forma de expresar su fortaleza o bien como una realidad, una torre cubierta con chapas de hierro ${ }^{120}$. Tenemos casos similares en documentación del siglo XIII de la campiña de Córdoba, una Torre del Hierro ${ }^{121}$.

Torre del Hierro es citada junto con otras heredades en documentos de principios del siglo $x V^{122}$.

\section{- TORRE DEL SALVADOR}

En la localidad de Almendral de la Cañada, sector norte de la Sierra de San Vicente, se encuentra la antigua torre del Salvador, de la iglesia del cementerio que tiene importantes reformas del siglo xVIII. Según algunos autores, sobre una antigua torre romano-islámica, se amplía y reedifica en época cristiana para el control del paso de ganados por la cañada real ${ }^{123}$, antiguo camino andalusí de comunicación entre Talabira y las cabeceras del valle del Alberche, llegando hasta el poblado de Peña Muñana en Cadalso de los Vidrios ${ }^{124}$. Como en otros casos, en torno a la torre vigia empieza a crecer el asentamiento repoblador y en el siglo XIII la utilizan como torre de la primitiva iglesia ${ }^{125}$.

118 Situada en la finca de la Oliva en término de Villar del Pedroso (Cáceres). Vid. JIMENEZ DE GREGORIO, "Castillos, torres...", p. 183-184.

119 PACHECO JIMÉnEZ, “Almunias medievales... », pp. 382-383.

120 PEREZ DE TUDELA et al. Arquitectura militar castellano-leonesa: Significado histórico y Glosario (ss. VI-XIII). Madrid, Castellum, 1991, p. 134.

121 F. SANChez VILLAESPESA, "Las torres de la Campiña de Córdoba en el siglo XIm. Un sistema de defensa de las comunidades rurales en época almohade» en Qurtuba, estudios andalusies, n. ${ }^{\circ} 1$ (1996), p.169.

122 Gomez Menor, p. 147, Sentencias del Deán Riaza de 1418

12.3 J. A. Chavarria Vargas, "El Valle del Tiétar en la Marca Media de Al-Andalus (Al-Tagr al-awsat)" en Trasierra, n. 2 (1997), pp. 95-112.

124 S. MARTINEZ LILLO y otros, “El poblamiento medieval en el curso medio-alto del río Tietar (Avila). La influencia del entorno", Actas del IV Congreso de Arqueologia Medieval Española. Alicante, 1994, pp. 345-358.

125 J. Sanchez GIL, La historia de El Almendral hasta finalizar el siglo xix. Toledo, 1998, p. 11. 


\section{- TORREJÓN}

Término de Calera y Chozas. Al igual que la Torrecilla, estaba cerca del despoblado de Zurrasbotas. En ambos casos hay evidencias arqueológicas de presencia romana en la zona pero el poblamiento medieval no sería de gran relevancia hasta al menos el siglo XIII cuando se empieza a poblar este sector, próximo a Alcolea y Alcañizo. No obstante los dos topónimos son indicativos del sistema defensivo en este ámbito rural. En 1411 se cita en una particion de Fernan Alvarez de Toledo: "Que el dicho Diego Lopes mi fijo aya i herede todos los bienes i heredat que yo he en Sotogordo i Torrejon çerca de la puente del Arçobispo que son en termino de Talavera»" ${ }^{126}$.

\section{- TORREJÓN DE LA ALCOBA}

Término de Talavera de la Reina, al oeste de la ciudad y entre las poblaciones de Talavera la Nueva y Alberche del Caudillo. Se mantiene el topónimo en la finca.

Al igual que en la Alcoba, se han documentado restos arqueológicos anteriores, de época romana, entre ellos una necrópolis excavada en los años $30^{127}$

No cabe duda de la presencia de una fortificación vinculada a la zona de huertas de Talavera, y relacionada con el lugar de la Alcoba. De hecho en la documentación bajomedieval suelen aparecer juntas. El topónimo torrejón o torrejones que se da en algún otro lugar de la comarca parece responder a la forma castellana de denominar restos de torres o atalayas de cronología plenomedieval.

De 1430 data un traslado de varios documentos muy clarificadores de la toponimia de estos enclaves ${ }^{128}$. Se recogen en este traslado varias escrituras relacionadas con las huertas, casas y torre de Torrejón de la Alcoba:

- Escritura de 9 noviembre de 1346.

“...las casas e la huerta e las heredades de Alcoba que disen de la Torre, las quales dichas casas e huerta e heredamientos se tienen con heredades de Alcoba la que disen de la eglesia...e con Adarallahuy..."

"...otorgamos e conosçemos que vendemos a uso Juan Peres de Villalobos...la meytad que nos auemos en todas las casas e la torre e la huerta e en todos los heredamientos e tierras para la buestra por pan e en los prados e pastos e aguas de Alcoba aldea que disen de la Torre que es en el señorio de Talauera..."

"...con heredades de alcoba la que disen de la eglesia ...e con heredades de Alcoba del pinarejo...e con heredamientos de Darallahuy..."

"...morador que es en Talauera al aldea que disen Alcoba de la Torre que es término de Talavera..."

126 A.H.N. Nobleza, Frias, sig. $1.252 / 25$

127 M. MAURA Y SaLAS: Excavaciones en una necrópolis romana de Torrejón (Talavera de la Reina)" en Anuario de Prehistoria Madrileña, II-III (1931-1932), pp. 93-98.

17 A.H.N., Nobleza, Frias: Leg. 572 /n." 1: 1430, enero, 11. Talavera. "Traslado autorizado de las escripturas de pertenenzia de las casas, huerta y heredades de la Aldea de Torrejón de la Alcova, en jurisdiçión de la villa de Talabera que pertenezian a la yglesia de Santa Maria la mayor de dicha villa..." 
- Escritura de 6 de junio de 1391:

"...unas tierras erias que fueron viñas con las vides e árboles que...son en el pago de Alcova término de Talavera".

- Escritura de 18 de marzo de 1410.

"...otrosi vendo vos mas todas las tierras que yo he Torrejón aldea e término de la dicha villa çerca las alcobas que alinda la dicha aldea con la heredad del alcoba de la eglesia e con el alcobilla e con tierras de Darallahuy e con tierras de Alvientreda..."

"...otrosi vendo uso todas las tierras que yo he en las Tapielas que es çerca del dicho logar Torrión con los aflores e pino e parrales..."

En otra ocasión hemos planteado la hipótesis de que se tratase de una fortaleza de origen romano vinculada al control de la vía romana de Emerita AugustaCaesarobriga (Talavera de la Reina) que pasaba cerca de aquí ${ }^{129}$.

\section{- TORRELAMORA O TORLAMORA}

En la zona de Carrascalejo, provincia de Caceres, pertenecia a la jara extremeña. En el siglo XVI se conservaba parte un muro de mamposteria de la presunta torre. Constituyo la base de una pequeña aldea cristiana en el proceso repoblador ${ }^{130}$. En 1516 aparece como lugar perteneciente a la parroquia del Villar del Pedroso ${ }^{131}$.

\section{- TORREMOCHA $=$ ALJARICHE o AL(H)ARICHE}

Junto al Tajo, en término de Calera, frente a los Aflejes. Cercana a Palomares ${ }^{132}$

Su etimología: Al-Xarij: “Hawmat alxarij: alquería de Aljariche» ${ }^{133}$. Una documento de 1216 recoge como Don Antolín vende al fraile don Juan, representante del Monasterio de San Clemente de Toledo, el tercio de un octavo de otra noria en el pago de Aljarich ${ }^{134}$. González Palencia lo identifica con Torremocha: hwmat tur(r)muja ${ }^{135}$. De tratarse del mismo enclave estamos ante un ejemplo de alqueria con torre de refuerzo defensivo.

Otras fuentes sitúan una Torremocha entre las fortalezas de Vascos, Castros y Azután, posiblemente junto a Alcolea de Tajo ${ }^{136}$

9 C. PACHeco Jimenez, "Fortificaciones y vias de comunicación...", op. cit. p. 61

30 JIMENEZ DE GREGoRIO, «Castillos, torres..." p. 180.

131 P. A. Lopez GayarRe, “Un vecindario de la antigua tierra de Talavera. 1516» en Homenaje a Fernando Jiménez de Gregorio. Madrid, 1991, p. 139 y ss.

132 Este topónimo aparece todavia en la cartografía del M.T.N. en edición de los años 1950. Sobre Palomares ver el apartado correspondiente a estos topónimos, en los que subrayamos la correspon. dencia entre las torres y los palomares.

133 Ferrando Frutos, El dialecto andalusi de la Marca Media: Los documentos mozárabes toledanos de los siglos $x \|$ y $x$ III. Zaragoza, 1995.

134 Gonzalez Palencia, op cit., doc. 432

135 FerRando Frutos, op. cit., p. 240.

136 Jimenez de Gregorio, "Castillos, torres..." p. 184. J. Gonzalez, Repoblación de Castilla la Nueva. Madrid, 1975, vol, I, p. 223. 


\section{- TORRES SALINAS}

Término de Talavera de la Reina, al NE de la ciudad.

$\mathrm{El}$ actual palacio tiene cuatro torres esquineras y casi todo el conjunto responde a un prototipo de edificación del siglo XVI. Conserva sin embargo restos de una torre medieval en su ángulo SW, la "torre mocha" que presenta en su base una tipología constructiva islámica, y en la parte superior una reforma cristiana ${ }^{137}$. La disposición de palacio-fortificado con planta quadribugium, según refiere Pavón Maldonado $(1999,145)$, plantea la posibilidad de una readaptación tardia de un alqasr o alcázar rural cuya finalidad estuviera ligada al control de las salinas cercanas:

- 1152: Se menciona el Arroyo Salinas en la delimitación del término del concejo de Avila con el de Talavera, por Alfonso VII ${ }^{138}$.

- 1197: Alfonso VIII concede a la Orden de Monfragüe y a su maestre Rodrigo Gonzálvez una renta anual de 15 cahíces toledanos de sal en las salinas de Talavera (en Torre Salinas) ${ }^{139}$.

Hemos querido también vislumbrar una presunta identificación de este palacete o almunia fortificada con la que se menciona en la leyenda de Enalvillos ${ }^{140}$, recogida en la crónica de Talavera de 1651, de Cosme Gómez Tejada de los Reyes. En una parte de! relato se menciona un palacio y «jardín» del gobernador de Talavera, a las afueras de la ciudad, como a una milla y media. Este estaba con uricos hospedamientos bien adornados, e emparamentados con ricos escaños, e le mostró los baños que avia, e les guió al palaçio donde eran las tablas (mesas) para yantars ${ }^{141}$.

Aunque puede resultar aventurado identificar por esa referencia geográfica este palacio con el de Torres Salinas, la existencia de los indicios arqueológicos citados, junto con la proximidad con Talavera convierten a este enclave en un candidato posible, hasta el punto de considerar a Torre Salinas una antigua almunia fortificada ${ }^{142}$

137 La torre tiene en la parte baja hiladas de mamposteria con sillares esquineros reutilizados probablemente de una construcción anterior califal. La cimentación se dispone escalonada, técnica que encontramos en las torres de la fortaleza califal de Talavera.

is Gómez MenOR, op. cit., p. 9

139 AHN, OO.MM., Registro escrituras de Orden de Calatrava I, sig. 1341, c. fol. 141

140 El episodio de Nalvillos se narra en la Crónica de la población de Avila, Valencia, 1966, pp. 27-29), pero su desarrollo varía de la trama que Tejada de los Reyes ncs describe, posiblemente fruto de una ampliación más literaria que histórica. En el trasfondo del asunto aparece lezmin Hiaya como señor de la Talabira islámica, durante la ocupación almorávide, enfrentado con el caballero abulense Nalvillos que consigue dar muerte al musulmán. En definitiva lo que traduce es el azote del concejo abulense a la Talavera islámica en el siglo XII para hacer frente a la amenaza almoravide.

14. Cosme G. TeJadA de los Reyes, Historia de Talavera, antigua Elbora de los Carpetanos, sacada a iimpio por Fray Alonso de Ajofrin...Talavera, 1651. Bib. Nacional, Mss. sign, 8.396, libro 2.", cap. 21.

142 Pacheco Jimenez, “Almunias medievales...”, p. 383. 


\section{- TORRICO, EL}

Actualmente municipio cerca de Valdeverdeja, y antiguamente formaba parte del señorio de Oropesa ${ }^{143}$. Como en otros ejempios, la existencia de una primitiva torre o atalaya parece ser el origen del poblamiento medieval. Moreno Nuñez asegura que Torrico y Alcolea cumplían las mismas funciones defensivas que las fortalezas del otro lado del Tajo, aunque más alejadas y en su ribera norte ${ }^{144}$.

\section{- TORRIQUILLO}

Entre los términos de El Villar del Pedroso y Valdelacasa de Tajo, en la jara cacereña. Se registran ya en $1418^{145}$ y en un deslinde de la Dehesa del Torriquillo de 1485 se recogen algunos datos de interes para su caracterizacion: “...e dise en esta guisa que comiença desde el arroyo de Pedroso a donde el arroyo de Fuente Vieja que va por la cuerda arriba fasta en par de la dicha fuente vieja e la dicha fuente dentro en la dicha dehesa en la mano ysquierda e va a dar a la boca de Valdelasierpe e atrauiesa el dicho valle e va a dar por ençima de la torrezilla de Torrequillo e dende atraviesa el camino que viene del Villar a Espejel e dende va a un valle que disen de la Torrezilla e atraviesa el dicho valle por encima de unos villarejos e va a dar al camino que va del Torriquillo a Valdelacasa e atraviesa el dicho camino por la cabeçada de las heras de Torriquillo e dende va a dar al camino que va desde el Torriquillo a Briuguilla ${ }^{146}$ allende una enzina questá ençima de un çerro la qual dicha ensina tiene fecha una cruz e dende va por un çerro ayuso fastta dar en el dicho arroyo de Piçarroso al molinillo e traviesa el dicho arroyo e va por una ladera arriba por ençima de la Peña del Cuervo e va a dar al arroyo de Mayoreja e dende el valle ayuso fasta dar en la Canaleja e dende Piçarroso ayuso fasta Castrejón y a la boca del dicho arroyo de Fuente Vieja a donde començó la dicha dehesa e aqui se acaba e çierra la dicha dehesa por la raya antigua" ${ }^{147}$.

\section{- TORTOLAS}

En término de Calera y Chozas, al SW del pueblo, y próximo al Tajo.

En documentos del siglo xv aparecen con el nombre de Torcolas ${ }^{148}$. Posible derivación de Torre. Como sucede con otros enclaves donde hay presencia o indicios documentales de turres cerca de la casa-palacio de Tórtolas se localizan restos de alguna villa o casa de campo romana.

14 Pertenecía el lugar a doña Maria Toledo Quiñones que en 1447 lo vende a Fernan Alvarez de Toledo, señor de Oropesa.

1.44 Moreno Nunez, "Fortalezas en el extremo meridional...", op. cit., p. 34.

145 En las Sentencias del Deán Riaza de ese año. Vid. Gomez MENor, op. cit.

146 Vid. el topónimo Briuguilla.

147 A.M.T ${ }^{a}$, Jurisdicción. Sig. 1.007. Talavera. 2 de febrero de 1485.

148 Archivo Histórico Nacional, Mesta, caja 195, n. 7 ; S. Ruiz Cafmona, "Las cañadas de Talavera y su tierra en el siglo Xv" en Cuaderna, 1 (Talavera, 1994). Gomez MEnOR, p. 147, Sentencias de 1492. 


\section{- TURRETRANCA}

Se trata de una heredad perteneciente a los Alvarez de Toledo, señores de Oropesa: "La heredad de Turretranca con sus pertenencias y con las tierras de la Cañada Vieja" ${ }^{149}$. Más tarde aparece, por degradación del topónimo, como Ejido de Orritranca (1546) ${ }^{150}$.

1.49 A. Franco Silva, "Oropesa: el nacimiento de un señorío toledano a fines del siglo xIV" en Anuario de Estudios Medievales, n. 15 (1985), p. 310.

150 AHN, Nobleza, Frias, leg. $580,2^{\circ} / 1325$. 